USD 544.225:546.27

K. Shirai (Mihogaoka, Ibaraki, Osaka, Japan)

\title{
Electronic structures and mechanical properties of boron and boron-rich crystals (Part I)
}

Boron and boron-rich crystals are hard materials, which have unique properties compared with other hard materials, such as diamond. Various ways of the arrangement of icosahedra yield many complicated crystal polymorphs and their derivatives. Although the crystals are basically hard, these are internally flexible for the mechanical and chemical properties. This flexibility is a consequence of conspiracy between the soft part and the hard part of the structure. The soft part is conveyed by the icosahedral unit, and the hard part is by the bonds connecting icosahedra. This article attempts to provide a consistent description for the unique characters of boron and boron-rich solids from the electronic-structure calculations. Recent developments of the first-principles calculation provide significant contributions to our understanding of the unusual properties of this class of materials. In particular, a combination of high-pressure experiment is successful in providing convincing evidence for our understanding, while it gives rise to unforeseen developments, such as discovery of superconductivity. Throughout analyses of many properties of boron solids, care is repeated for the effects of special arrangement of atoms and atom relaxation for those of complicated structures, which otherwise would mislead our intuitive interpretations. Special emphasize is placed on the phase stability and phase transitions at high pressure, because of recent successive discoveries of novel hard materials, such as $\gamma$-orthorhombic boron and diamond-like $B C_{5}$ compound. The first part of this review describes the ground state of boron and boron-rich crystals. The energy gap, native defects, and phonon properties are discussed.

Key words: rhombohedral boron, boron-rich crystals, first-principles calculation, icosahedron-based structure, native defects, electronic structure.

\section{INTRODUCTION}

Boron crystals occupy a unique position in the research of superhard materials. Boron is the second-ranked hard elemental crystals after diamond. Combinations with other light elements provide a variety of hard materials, such as $\mathrm{BN}$, boron carbides, $\mathrm{B}_{6} \mathrm{O}, \mathrm{BC}_{2} \mathrm{~N}$, etc. The list of such compounds has not yet been exhausted. Today, we have witnessed successive discoveries of hard materials around boron. Synthesis of diamond-like $\mathrm{BC}_{5}$ is our big surprise [1]. This is the hardest material ever reported, except diamond. Even in pure boron, a new polymorph of the highest density, $\gamma$-orthorhombic boron, has been discovered [2, 3] and later confirmed [4]. Related to superhard materials, an epoch making event in this field is the discovery of superconductivity in boron at high pressure in 2001, although pure boron is a semiconductor [5]. Since then, the superconductivity has been discovered in heavily doped diamond, which was first synthesized at high pressure [6]. This opens a new stream of superconducting research in heavily doped semiconductors [7-9].

In this context of the development of material research, it is legitimate to further search for hard materials around boron and its compounds, especially with high

(C) K. SHIRAI, 2010 
pressure techniques. For the diamond case, the structure is relatively simple and is well studied as the class of tetrahedrally-coordinated semiconductors. The mechanical and chemical properties are well described on the basis of the electronic structures. On the other hand, for the boron case, the study has not been well developed. There are many polymorphic modifications, whose structures are complicated, possessing icosahedra, $\mathrm{B}_{12}$, as the common building block. There are a variety of ways for the arrangement of icosahedra, together with additional structural elements. Notwithstanding, most of them belong to semiconductors or insulators. The structural flexibility of boron and boron-rich compounds largely depends on this unique structure of icosahedron. For the development of superhard material research, deep understanding for the special roles of icosahedron is indispensable. This is especially needed, considering that new applications have been explored in superconductivity [10] and thermoelectric research [11-14].

The primary purpose of this paper is to provide recent theoretical achievements in the electronic structures of rather complicated boron and boron-rich crystals. Their versatile electronic properties are described as consistently as possible. The central tool for studying the electronic structures is density-functional theory (DFT). There is no need for experimental data for predictions in the material research. Density-functional theory is a theory of ground states of materials, which is for today the most successful theory for numeric calculations. Most of the readers of this journal may be interested in the hardness. Although the macroscopic quantity hardness is a measurable quantity, it is not well founded from the quantum mechanical stand point. Elastic properties are well accommodated in DFT [15], as well as the cohesive energy and other useful energies. Elastic constant seems to be akin to the hardness, but these two quantities are not always correlated. This suggests that the hardness is not at all determined by the elastic constant solely. Qualification of the hardness by DFT is barely to begin recently [16-20]. Accordingly, the mechanical properties descried in this paper are limited to a level of elastic properties and phonon properties. On the other hand, our arguments include finite-temperature properties, which are formally regarded as being out of DFT treatment. As far as phonon properties are concerned, finite-temperature properties can be treated within DFT, which provide rich of physical interpretation.

Special care is taken in preparing this review. First, emphasis is placed on the interpretation of calculations in a coherent way, rather than merely juxtaposing numerical data. This way of description is specifically important for understanding such complicated materials. One risk of doing so is a prejudice against author's own opinion. Since the nature is so complicated, what we have learned from many DFT calculations is that most of properties of materials are determined by a subtle balance between many competitive factors. While interpreting a specific property, one usually emphasizes only one cause of the property, ignoring the others. This paper is of course not the exception. To avoid this risk, the readers are recommended to refer to original papers and other reviews. As the source of huge data on boron solids, comprehensive handbooks by Werheit [21, 22]. are available. Chemical properties are well documented in a series of handbooks [23]. For the material preparation, a volume written by Mueterties is invaluable [24]. A Japanese handbook is the most update source for the research development [25]. Everyone who is enthusiastic for the history of boron, can enjoy an article by Oganov and Solozhenko entitled "Boron: a Hunt for Superhard Polymorphs" [26]. Second, usefulness of high pressure research is emphasized. The roles of high pressure research are double. The one is a powerful tool to synthesize those novel materials, which are otherwise difficult to produce. The other is also a powerful tool to 
examine the physical and chemical properties. Throughout this paper, the reader will see how many things about the present status of the understandings of boron properties are owed to high-pressure studies. Third, an attempt is made to compare to other classes of crystals, as far as I can do. This makes the discussion more general and in effect would help the readers to acquire useful insights into superhard-material research.

Lastly, I like to stress that, although DFT is a powerful tool to study the microscopic properties of solids, the result of calculation alone does not automatically guarantee correctness of the interpretation. Many disagreements and debates concerning a specific interpretation are found in the literature. The reader may be surprised to see that entirely opposite interpretations, for example, soft and stiff, emerged for a particular bond. I should stress again that, in an experiment, one usually sees only one side of the whole story. The same is true for calculations too, if one inspects only one property. There is little doubt for regarding a balloon as a soft matter. However, one can find it difficult to compress it uniformly by holding with his hands. Sound usage of models for analyzing results is indispensable.

\section{CRYSTAL STRUCTURE}

\section{Icosahedron-based structure}

Elemental boron has many polymorphic modifications. The most commonly observed polymorph is $\beta$-rhombohedral boron, which is conventionally referred to as $\mathrm{B}_{105}$ but actually the structure is more complicated. A recent study shows that the unit cell contains 106.5 atoms [27]. The structural determination was made relatively lately [28] during the long history of boron research. Complicated defects have been successively discovered in the course of studies [29-32]. The icosahedron-based structure was first identified for boron carbide, which is formally referred to as $\mathrm{B}_{12} \mathrm{C}_{3}$ or more shortly as $\mathrm{B}_{4} \mathrm{C}[33,34]$. The true structures became more complicated as the study progressed [35-41]. The composition varies in some range, typically from $\mathrm{B}_{12} \mathrm{C}_{3}$ to $\mathrm{B}_{13} \mathrm{C}_{2}$, but more $\mathrm{C}$-poor compounds exist [42]. It is believed that the most $\mathrm{C}$-rich compound obtained so far is close to the composition $\mathrm{B}_{12} \mathrm{C}_{3}$ but is slightly less than that, which is sometime referred to as awkward name $\mathrm{B}_{4.3} \mathrm{C}[43,44]$. The simplest polymorph is $\alpha$-rhombohedral boron, which was isolated in 1959 [45]. These three phases have rhombohedral lattices. Meanwhile, several tetragonal phases were found. The discovery of $\gamma$ orthorhombic boron is a recent topic of this field.

In this paper, we are mainly concerned with three polymorphs, $\alpha$-rhombohedral boron, $\beta$-rhombohedral, and boron carbide, because of their basic importance. Figure 1 illustrates the structures of these polymorphs. The simplest structure of $\alpha$ rhombohedral boron is described by a rhombohedral network of icosahedra with crystal symmetry $R \overline{3} \mathrm{~m}$. If the apex angle $\alpha_{\mathrm{rh}}$ of the rhombohedral lattice is just $60^{\circ}$, the rhombohedral lattice is turned to a FCC lattice, and the icosahedron would have twelve nearest neighboring icosahedra. Actually, the apex angle $\alpha_{\mathrm{rh}}$ is slightly deviated from $60^{\circ}$ : slightly negative for $\alpha$-rhombohedral boron, and positive for both boron carbide and $\beta$-rhombohedral boron. Although the deviation is only slight, it has non-trivial consequences on the elastic response of this crystal, as shown later. The deviation of the apex angle $\alpha_{\mathrm{rh}}$ lifts the twelve intericosahedral bonds into two classes. The shorter one is the two-center intericosahedral bond, $r_{2}$, which is characterized as a usual covalent bond connecting two polar cites of an adjacent icosahedra. The other and longer one is the so-called three-center 
intericosahedral bond, $r_{3}$, connecting three equatorial cites as shown in Figs. 1 and 2. In this paper, the intericosahedral and the three-center center are referred to as the two-center intericosahedral bond and the three-centre intericosahedral bond, respectively.

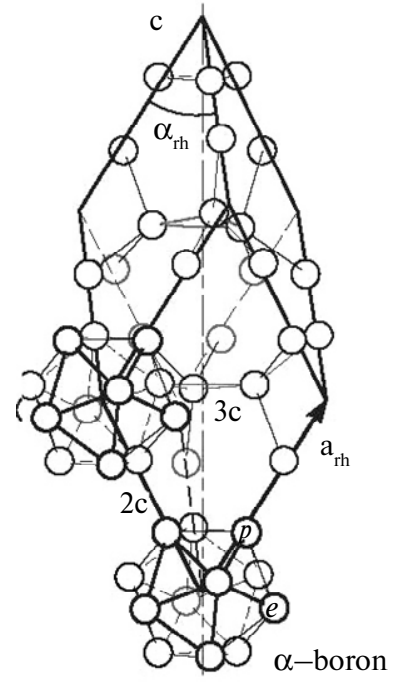

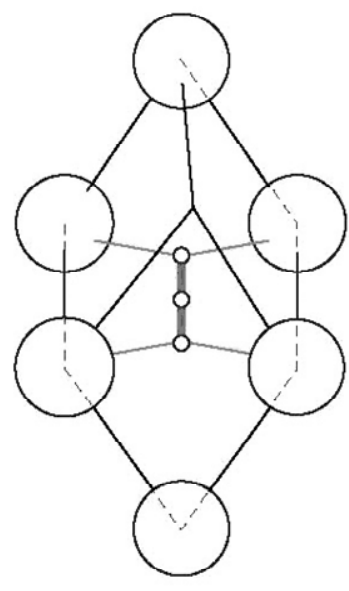

boron carbide

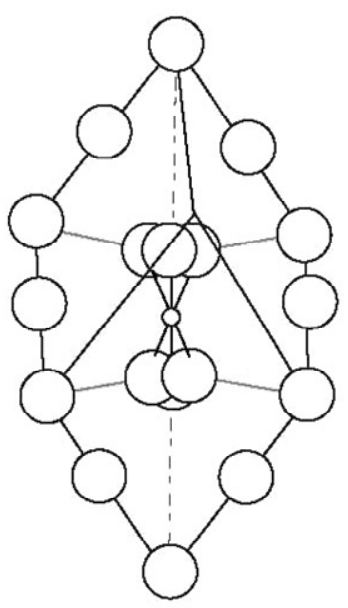

$\beta-$ boron

Fig. 1. Crystal structures of $\alpha$-rhombohedral boron, boron carbide, and $\beta$-rhombohedral boron. For the latter two, the icosahedron $\mathrm{B}_{12}$ is represented by spheres. In $\alpha$-rhombohedral boron, the stronger two-center intericosahedral bond is denoted by $2 \mathrm{c}$, whereas the weaker three-center intericosahedral bond is denoted by $3 \mathrm{c}$. In an icosahedron, there are two distinct sites: polar site $(p)$ and equatorial site $(e)$.

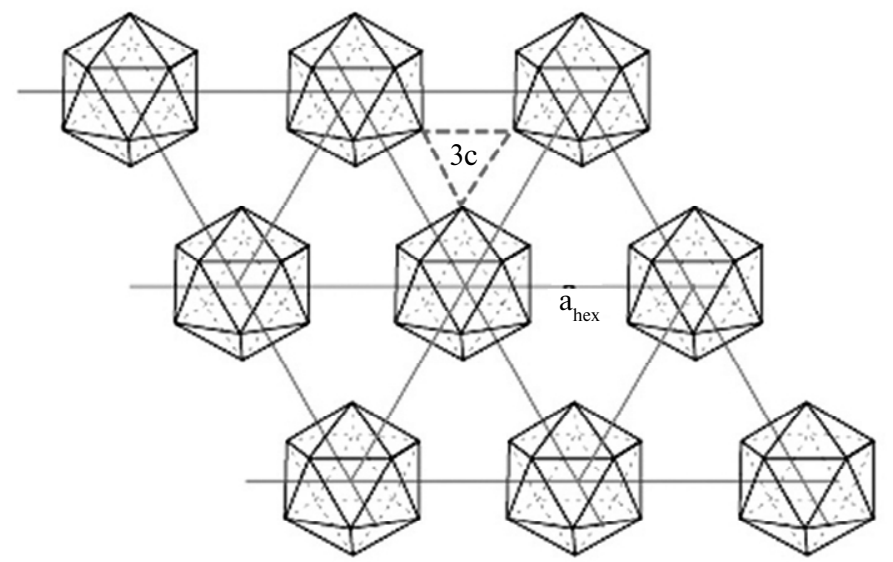

Fig. 2. Arrangement of icosahedra of $\alpha$-rhombohedral boron in the $a b$ plane.

For an icosahedron of $\alpha$-rhombohedral boron, there are six intericosahedral bonds, which are directed along with the cell vectors, but with a slight deflection. It is known that the length of the intericosahedral bond $r_{2}(1.71 \AA)$ is shorter than that of the intraicosahedral bond $(1.73-1.79 \AA)$. This fact gives definite evidence for the traditional understanding of strong intericosahedral bond. For this reason, the boron crystal is called inverted molecular crystal, contrasting to molecular crystals such as fullerides [12].

The six three-center bonds for an icosahedron lie on the $a b$ plane, as shown in Fig. 2, along with six nearest neighbour icosahedra. The three-centre bond is the 
bond with the longest bond length $\left(r_{3}=2.03 \AA\right)$ among various $\mathrm{B}-\mathrm{B}$ bonds in this system. Therefore, the three-center bond is weak, and is chemically active: it is the first place to enter when additional elements of structure are incorporated. In boron carbide, the weak three-center bonds are replaced with strong covalent bonds, on inserting $\mathrm{C}$ atoms (the middle of Fig. 1). For $\beta$-rhombohedral boron, the situation is more complicated, although a rough sketch of the structure looks like similar to boron carbide (the right of Fig. 1). Another way of describing $\beta$-rhombohedral structure is shown in Fig. 3. In this view, the basic building block becomes doublewalled icosahedron $B_{84}$, that is, an endohedral $B_{60}$ with a $B_{12}$ inside it. When viewed from $\mathrm{B}_{84}$ units, one sees multiple intericosahedral bonds (the middle of Fig. 3). However, if viewed from $B_{12}$ units, these intericosahedral bonds are turned out to be intraicosahedral bonds. In this way, in $\beta$-rhombohedral boron, the distinction between intericosahedral and intraicosahedral bonds is somewhat obscure. It is noted that, when viewed from $\mathrm{B}_{12}$ units, an icosahedron has approximately twelve nearest neighboring icosahedra. From this point of view, intericosahedral bonds are again shorter than any intraicosahedral bonds. This is seen from Table 3 of Ref. [46].

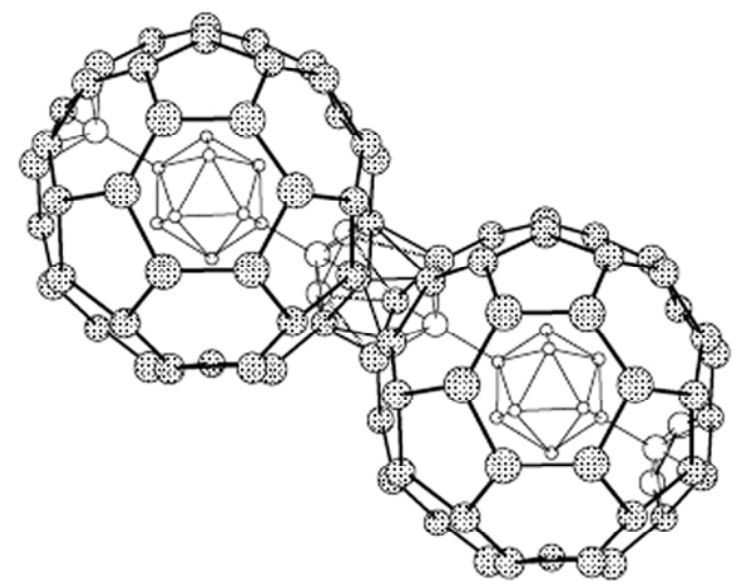

Fig. 3. Structure of $\beta$-rhombohedral boron. Two $\mathrm{B}_{84}$ units contact each other. At the contact face, another $\mathrm{B}_{12}$ unit is formed.

This trend that intericosahedral bond is shorter than intraicosahedral bond holds even for the recently discovered phase $\gamma$-boron $[3,47]$. Therefore, it is a common property for boron solids.

The physical properties of $\alpha$ - and $\beta$-rhombohedral boron are compared in Table 1 . In many respects, $\alpha$ - and $\beta$-rhombohedral phases show clear contrasts: many others fall in intermediate states between these two. Clearly, the $\alpha$ phase is the denser one, while the $\beta$ phase is the diluted one. As a result, the $\alpha$ phase is stiffer than the $\beta$ phase. Although this is a simple fact, the importance of the phase stability had not been recognized seriously until recently. Even the fact that the $\alpha$ phase is stiffer than the $\beta$ phase was not so obvious, when the author submitted the paper [46]. In fact, one of the referees criticized this point. The importance of the density becomes evident when stabilities of phases are investigated. As compared in Table 2, the lower density the crystal possesses, the higher temperature is required for the preparation. The mechanism of stability is similar to that of diamond and graphite. The dense phase diamond is stiff and stable at low 
temperatures and high pressures, while the dilute phase graphite is soft and stable at high temperatures and low pressures. This is a general trend, which is one of the consequences of thermodynamic stability [54].

Table 1. Structural parameters of $\alpha$ - and $\beta$-rhombohedral boron in experiment. Lattice parameters $a_{0}$ and $\alpha$, number of atoms $N_{\text {at }}$, atom density $\rho$, coordination number $N_{c}$, Debye temperature $\Theta_{D}$, and bulk modulus $B_{0}$. The bond length is presented as the minimum $d_{\min }$ and average $d_{\text {avg }}$ for all the bonds

\begin{tabular}{ccc}
\hline & $\alpha$ - rhombohedral & $\beta$-rhombohedral \\
\hline$a_{0}(\AA)$ & $5.057^{a}$ & $10.145^{b}$ \\
$\alpha\left(^{\circ}\right)$ & $58.06^{a}$ & $65.17^{b}$ \\
$N_{\text {at }}$ & $12^{a}$ & $105^{b}$ \\
$\rho\left(/ \AA^{3}\right)$ & $0.1373^{a}$ & $0.1278^{b}$ \\
$N_{c}$ & $5.50^{a}$ & $6.40^{b}$ \\
$d_{\text {min }}(\AA)$ & $1.71^{a}$ & $1.62^{b}$ \\
$d_{\text {avg }}(\AA)$ & $1.77^{a}$ & $1.80^{b}$ \\
$\Theta_{D}(\mathrm{~K})$ & $1430^{c}$ & $1200-1300^{d}$ \\
$B_{0}(\mathrm{GPa})$ & $213-224^{e}$ & $185-210^{f}$ \\
\hline
\end{tabular}

Note: ${ }^{a}[45] ;{ }^{b}[29,30] ;{ }^{c}[48] ;{ }^{d}[48-50] ;{ }^{e}[51] ; ;^{f}[51-53]$.

Table 2. The preparation temperature of various polymorphs of boron. The data are taken from Ref. [23]. For $\gamma$-orthorhombic boron, the data are taken from Ref. [3]

\begin{tabular}{c|c|c|c|c}
\hline Polymorph & $T_{\text {prep }},{ }^{\circ} \mathrm{C}$ & $N_{c}$ & $N_{\text {at }}$ & $V_{\text {at }}, \AA^{3}$ \\
\hline$\alpha$-rhombohedral & $\sim 1000$ & 5.5 & 12 & 7.2823 \\
$\beta$-rhombohedral & $>1100$ & 6.4 & 105 & 7.8533 \\
$\alpha$-tetragonal (I) & $\sim 1150-1300$ & & 50 & 7.7481 \\
tetragonal (III) & $\sim 1280-1500$ & & $\sim 192$ & 7.5424 \\
tetragonal (II) & & & $\sim 78$ & 7.6552 \\
$\gamma$-orthorhombic & & & 28 & 7.0884 \\
\hline
\end{tabular}

\section{Defects}

The significance of defects in boron-rich solids may be different from the situation of typical semiconductors. The defect of boron-rich solids should be viewed as a part of the host structures. For a long time $\alpha$-tetragonal structure, $B_{50}$, was believed to be a polymorph of boron [55], but actually the crystal was proven to be $\mathrm{B}_{50} \mathrm{~N}_{2}$ or $\mathrm{B}_{50} \mathrm{C}_{2}$ [56-59]. The crystal is stabilized only by inclusion of impurities. Therefore, it is now almost accepted that pure $\alpha$-tetragonal form cannot exist. However, there is a possibility that pure $\alpha$-tetragonal boron exists in nanocrystals; see [60] and the references therein. A compound $\mathrm{AlB}_{12}$ can be also regarded as a crystal whose structure is stabilized by impurity [61-63]. For boron carbides, the crystals are from beginning disordered systems. In Table 3, the defect concentrations of boron-rich solids are compared. Why the crystal has defects of such a high concentration is one of the main issues for which theory has to give the answer. 
Table 3. The point defect concentrations in boron crystals [41]. For the original sources of the numeric values the cited paper [41] is referred to

\begin{tabular}{|c|c|c|c|c|c|}
\hline \multicolumn{4}{|c|}{ Idealized crystal structure } & \multicolumn{2}{|c|}{ Real crystal structure } \\
\hline $\begin{array}{c}\text { valence } \\
\text { states (per } \\
\text { cell) } \\
\end{array}$ & \begin{tabular}{|c|} 
valence \\
electrons (per \\
cell)
\end{tabular} & $\begin{array}{l}\text { electron } \\
\text { deficiency } \\
\text { (per cell) }\end{array}$ & $\begin{array}{l}\text { electronic } \\
\text { character } \\
\text { theoretical }\end{array}$ & $\begin{array}{c}\text { electronic } \\
\text { character } \\
\text { experimental }\end{array}$ & $\begin{array}{c}\text { intrinsic } \\
\text { point defects } \\
\text { (per cell) }\end{array}$ \\
\hline \multicolumn{6}{|c|}{$\alpha$-rhombohedral boron } \\
\hline 36 & 36 & 0 & semiconductor & semiconductor & 0 \\
\hline \multicolumn{6}{|c|}{$\beta$-rhombohedral boron } \\
\hline 320 & 315 & 5 & metal & semiconductor & 4.92 \\
\hline \multicolumn{6}{|c|}{ boron carbide } \\
\hline \multicolumn{6}{|c|}{$\mathrm{B}_{13} \mathrm{C}_{2}$, idealized structure formula: $\mathrm{B}_{12}(\mathrm{CBC})$} \\
\hline 48 & 47 & 1 & metal & semiconductor & 0.97 \\
\hline \multicolumn{6}{|c|}{$\mathrm{B}_{4.3} \mathrm{C}$, idealized structure formula: $\mathrm{B}_{11} \mathrm{C}(\mathrm{CBC})$} \\
\hline 48 & 47.83 & 0.17 & metal & semiconductor & 0.19 \\
\hline \multicolumn{6}{|c|}{ hypothetical $\mathrm{B}_{4} \mathrm{C}$, idealized structure formula: $\mathrm{B}_{11} \mathrm{C}(\mathrm{CBC})$} \\
\hline 48 & 48 & 0 & semiconductor & - & - \\
\hline
\end{tabular}

Standard band calculations predict that $\mathrm{B}_{12} \mathrm{C}_{3}$ is a semiconductor, while $\mathrm{B}_{13} \mathrm{C}_{2}$ is a metal. Experimentally, at normal conditions, boron carbides show up as if degenerate semiconductors over all the composition range [22, 64].

\section{ELECTRONIC STRUCTURE}

Density-functional theory treats the ground states of materials. In this section, what DFT calculations tell us about the ground states of boron is described. In most of this section, $\alpha$-rhombohedral boron is investigated, because the structure is simply enough for theoretical analysis and yet complicated to see the roles of the icosahedral structure. Analysis of $\alpha$-rhombohedral boron is relatively simple, but experimentally it has not been well studied, because of the difficulty of sample preparation. Thus, it is not surprising that the first experiment of superconductivity was examined on $\beta$-rhombohedral boron [5]. Recently, the superconductivity of $\alpha$ rhombohedral boron has been discovered at about $160 \mathrm{GPa}$, similar to $\beta$ rhombohedral boron $[65,66]$. From the theoretical side, this finding is of a significant importance, for the difficulties of structural study on $\beta$-rhombohedral boron can be avoided. A structural study at high pressures up to $200 \mathrm{GPa}$ has been carried out, demonstrating that the structure of $\alpha$-rhombohedral boron is stable up to this pressure, and that a gap closure occurs without any phase transition $[67,68]$. An electronic structural study reveals details of the metallization process and the nature of bonding of boron [69]. With this new development in mind, the electronic structure of $\alpha$-rhombohedral boron is reviewed in the following.

\section{Preliminary: molecular orbital theory}

To understand the bonding nature of boron solids, a chemist's approach of the counting rule, i.e., how the valence electrons satisfy the bonding requirement, is useful. The chemical bonds of boranes are characterized as electron deficient systems [70]. The element is of column III, and therefore one electron is deficient for forming a covalent bond. In boranes, such as $\mathrm{B}_{2} \mathrm{H}_{6}$, a fewer number of valence 
electrons have a propensity for being shared by many atoms. The concept of threecenter bond was conceived to describe this nature of the chemical bonds [71]. A natural extension of the molecular orbital theory to solid boron was made by Longuet-Higgins, who investigated the molecular orbitals of the $\mathrm{B}_{12}$ unit [72]. A $\mathrm{B}_{12}$ molecule has 13 intraicosahedral bonding orbitals, which are fully occupied by 26 electrons. The remaining 10 electrons are distributed among 12 outwardoriented orbitals. Accordingly, two electrons are deficient for fulfilling the bonding requirement of the $B_{12}$. This is a key issue for understanding of the bonding nature of $B_{12}$ unit: although $B_{12}$ is a favourable unit for satisfying the bonding requirement of boron atoms, $\mathrm{B}_{12}$ by se is not so stable.

To supply the two deficient electrons, boron atoms tend to gather each other by forming triangles or polyhedra. This is an economical way for a small number of electrons to meet the bonding requirement. This gives a reasonable account for the fact that there are many stable (or metastable) polymorphs that have complex structures, e.g., $\beta$-rhombohedral, tetragonal- I, -II, and -III [23].

After Longuet-Higgins' work, a number of more accurate calculations were carried out for the electronic structure of $\alpha$-rhombohedral boron [73, 74], including modern density functional calculations [75, 76]. Even performing DFT calculations, the qualitative aspects given by Longuet-Higgins are still valid. However, in DFT calculations, the attribution of a definite number of electrons to specific bonds loses its strict meaning, because the charge density is distributed continuously everywhere $[75,76]$.

Replacing the weak three-center bonds by strong covalent bonds is a way, which is commonly observed in B-rich compounds, such as $\mathrm{B}_{12} \mathrm{P}_{2}, \mathrm{~B}_{12} \mathrm{As}_{2}$, and maybe $\mathrm{B}_{12} \mathrm{C}_{3}$. All the foreign atoms form a linear chain along the main diagonal of the rhombohedral unit cell. In boron carbide, the role of insertion $\mathrm{C}$ chain seems qualitatively different from the others. An analysis of the phonon spectrum indicates that the presence of the $C$ chain enhances the chain bond itself, while weakens the intraicosahedral bonds [77]. The structure of $\beta$-rhombohedral boron seems to indicate another way of eliminating the three-center bond of $\alpha$ rhombohedral boron. However, the stability of $\alpha$ - and $\beta$-rhombohedral boron turns out to be different, as seen in the following.

\section{Density functional theory}

A great merit of DFT calculations is the capability of calculating the total energy of crystals, whichever method is used. From the total energy, crystal structures can be optimized and can be compared between different structures, resulting in the high accuracy for electronic-structure calculations.

Electronic structure of $\alpha$-rhombohedral boron. Although the qualitative understanding of Longuet-Higgins still survives, the picture of molecular orbitals is obscure in solids. Comparison of the electronic structure of $\alpha$-rhombohedral boron to that of $B_{12}$ molecule shows that strong intermixing of the valence bands occurs, so that it is difficult to say which band corresponds to which molecular orbital of $\mathrm{B}_{12}$, except the lowest-lying bands $[78,79]$. This fact itself evidences the strong intericosahedral bonding.

In all of major calculations of $\alpha$-rhombohedral boron, the calculated lattice parameters show good agreement with experiment: within 1 to $2 \%$ in LDA and $0.2 \%$ in GGA [68, 75, 80, 81]. In this respect, GGA is better than LDA. Most of published studies were performed by pseudopotential method, where the core electrons are treated as rigid cores. In the investigation on a peculiar bond as 
described shortly later, the effect of core electrons has been examined. In our experience, the nonlinear core correction has no discernible effect on the physical properties of boron [82].

The covalent-bond character, i.e., highly oriented bond, of the intericosahedral bond is evident by looking at the charge distribution, as shown in Fig. 4. All the DFT calculations thus far published show that the maximum of charge distribution occurs at the center of the intericosahedral bond suggesting the strongest bond [68, $75,81,83]$. The character of the intericosahedral bonding as the strongest bond does not change at high pressures, surprisingly even after the metallic transition $[69,81]$. This is seen in Fig. 4. Related to this bond, experimentalists derived a peculiar charge distribution by the maximum entropy method for powder X-ray diffraction $[84,85]$. In all the DFT calculations, such a strange distribution is not obtained. This interesting discrepancy is being in consideration. The charge distribution of the three-center bond is shown in Fig. 5. The charge is distributed over the triangle formed by the neighboring three atoms. As pressure increases, more charge is accumulated at the center of the triangle. Other aspects of the charge density are described in [83] and [75].
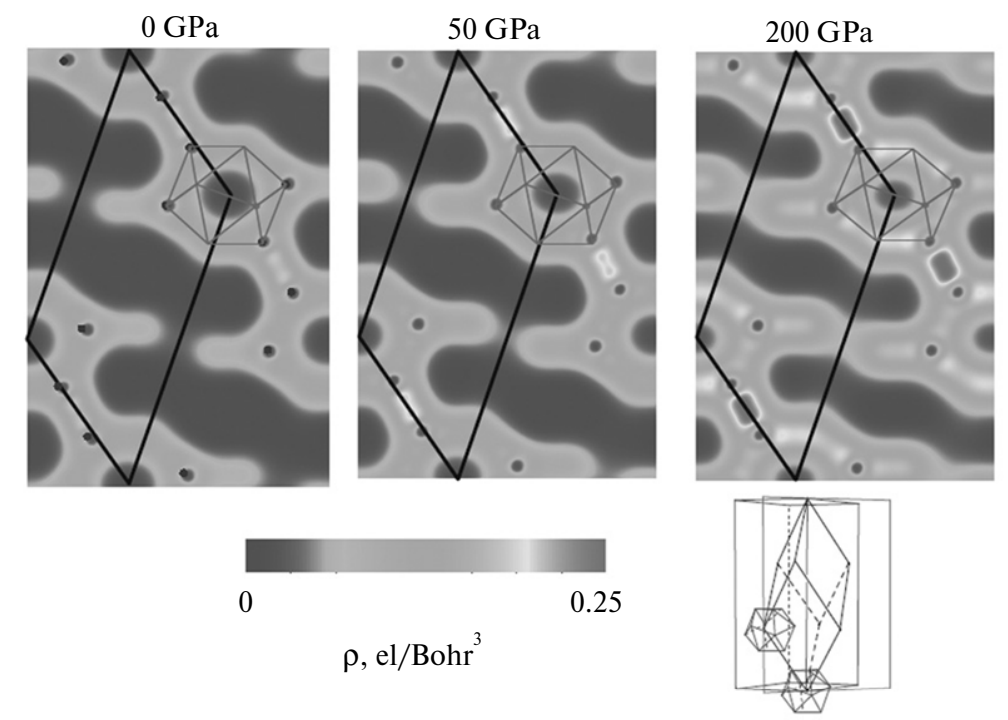

Fig. 4. Charge distribution of $\alpha$-rhombohedral boron as a function of pressure. The cut plane is shown in the bottom right of the figure [68].

The band structure of $\alpha$-rhombohedral boron is shown in Fig. 6. Similar diagrams are found in the literature, but the present diagram has a merit of providing a full classification of symmetry. The basic electronic structure of $\alpha$ rhombohedral boron is characterized as an indirect semiconductor: the top of the valence band is at the $Z$ point, while the bottom of the conduction band is at the $\Gamma$ point [75]. In Fig. 6, the energy gap $E_{g}$ is seen to be $1.62 \mathrm{eV}$.

In the literature, $E_{g}$ is reported as $1.43 \mathrm{eV}$ by Lee et al. [75] and $1.2 \mathrm{eV}$ by Zhao and $\mathrm{Lu}$ [81] in the LDA, and as $1.72 \mathrm{eV}$ by Zhao and Lu [81] in the GGA; the values of $E_{g}$ are scattered in this extent.

In the literature, it is sometimes stated that GGA is better than LDA [81]. However, for the gap problem, GGA cannot be regarded as the next-order approximation to LDA $[86,87]$. In our calculation, when LDA is replaced with GGA by fixing other conditions, the gap changes only by $0.01 \mathrm{eV}$. If GGA 
calculation improves the band gap, this must be ascribed to the fact that GGA improves the structural parameters.
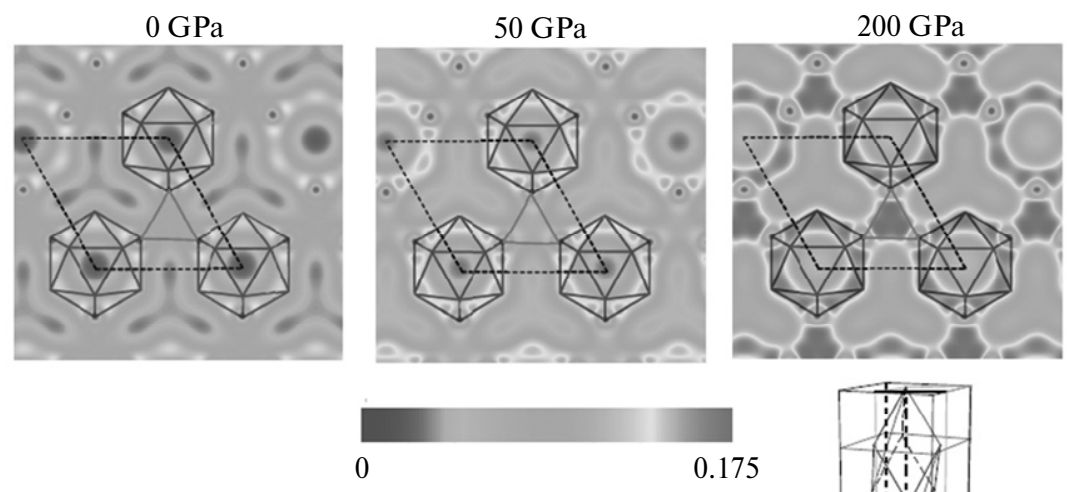

$$
\rho, \mathrm{el} / \mathrm{Bohr}^{3}
$$

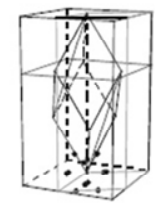

Fig. 5. Charge distribution of the three-center bond in $\alpha$-rhombohedral boron as a function of pressure. The cut plane is shown in the right-hand figure [68].
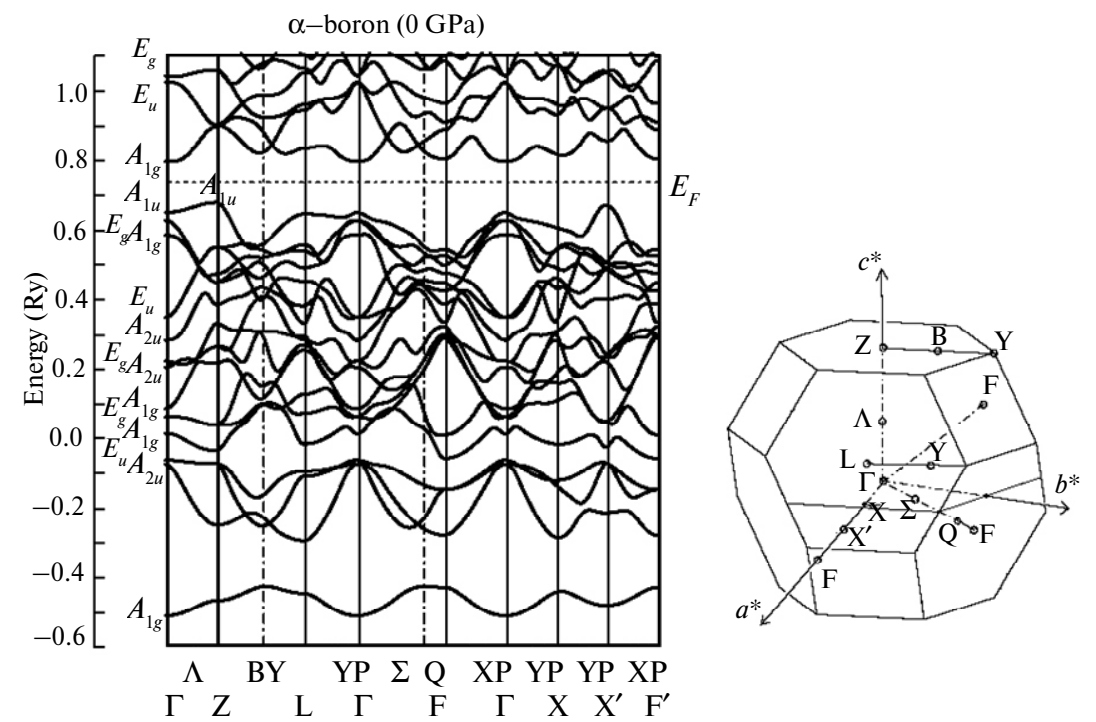

Fig. 6. Band structure of $\alpha$-rhombohedral boron. The names of symmetry points and lines in the Brillouin zone are indicated on the right-hand side [69].

The experimental value of the gap is $2.0 \mathrm{eV}$ from resistivity measurements, whereas it has been shown to be 1.9 to $1.96 \mathrm{eV}$ from optical measurements [8891] and $2.4 \mathrm{eV}$ from electron energy loss experiments [92]. Hence, all the DFT calculations show smaller values than the experimental values, which is a situation common in DFT calculations. For boron solids, the electronic conduction mechanism is very complicated. For $\beta$-rhombohedral boron and boron carbides, there are many models and discussions to account for their unusual behaviours [11, $14,27,41,64]$. That the electronic transport is conveyed by the hopping of a carrier between defect sites is the only point on which most of researchers can agree. There are many debates as to the nature of the electronic defects. Only for $\alpha$ rhombohedral boron, the conduction characteristics accord to the standard mechanism of band conduction, which has been recently shown by the pressure 
dependence of the resistivity [69]. The hole character of the conduction is due to the flatness of the conduction bottom, which means a heavy mass of electrons. Because of this flatness, the conduction band has a bowing at high pressure, as discussed in the next subsection.

Pressure dependence. Pressure dependence of the electronic structure provides many fruitful insights in our understanding of the bonding nature of boron. A continuous gap closure of $\alpha$-rhombohedral boron was theoretically predicted by Zhao and $\mathrm{Lu}$ [81]. The pressure of gap closure is $160 \mathrm{GPa}$. Now, we know that at this pressure a superconducting transition occurs without any phase transition [67]. The crystal structure of $\alpha$-rhombohedral boron is stable up to $200 \mathrm{GPa}$. The intericosahedral bond enhances its covalent character as the pressure increases. Despite, it is surprising to see that the metallic transition takes place. The mechanism for this metallization has been given by Zhao and Lu [81]. Although the intericosahedral two-center bond is still the strongest, the most significant change occurs in the intericosahedral three-center bond. At low pressures, the three-center bond is so weak that an icosahedron has only six-fold coordination, which is a typical situation for semiconductors. At high pressures, the bond length of the three-center bond is rapidly shrunk, so that the coordination number of the icosahedron increases close to 12 , which is a typical situation for metals.

In a general sense, this interpretation based on the coordination number may be sufficient for a qualitative account for the metallization mechanism. However, caution is needed for boron crystals [68]. For $\beta$-rhombohedral boron, the coordination number of icosahedron is 12 even at ambient pressure, yet the crystal behaves as semiconductor. The coordination number alone is not sufficient to decide as to whether the crystal is a metal or insulator. A band-structure calculation shows that the conduction bottom (C.B.) band is characterized as the bonding state of the three-center bond. After the gap closing, electrons of V.T. band are transformed to the C.B. band. In the real space, this can be interpreted as electrons are transformed from the intraicosahedral bonds to the three-center bonds, leaving the Fermi surface in the V.T. band.

Plotting of wave functions is useful to see the change of bonding nature. The wave function of C.B. is shown in Fig. 7. In the figure, one can see that the C.B. band has a bonding character for the intericosahedral bonding and for the threecenter bonding, and an antibonding character for the part of the intraicosahedral bond. The bonding characters of V.T. and C.B. bands obtained in this way are summarized in Table 4 [69].

These bonding characters of wave functions are evident when doping of impurity is applied to $\alpha$-rhombohedral boron. On electron doping in $\alpha$-boron, the icosahedra are nearly always deformed as elongation along the crystal $c$-axis [93]. This is a consequence of the antibonding character for the intraicosahedral $\mathrm{B}(p)$ $\mathrm{B}(e)$ bond part in the C.B. band. A more remarkable effect is seen in hydrogen doping. Most impurity atoms enter to $\alpha$-boron at the center of the lattice $(O$ site $)$ [94]. Differently from other impurities, hydrogen atoms enter near the center of the three-center bond ( $T$ site) [95]. Consequently, the three-center bond is strongly enhanced, so that the level of the C.B. band significantly decreases to completely fill the energy gap.

When applied high pressure or doping, the effect of the three-center bond comes to play a role, and eventually yields metallization. It is interesting to see a marked difference in the pressure dependence of the gap between boron and diamond. For diamond, it is argued that a large difference in the radius of atomic orbitals between the valence and excited $d$ states prevents the diamond structure 
from transforming to metallic phases such as FCC [96]. For boron, the geometric effect of icosahedra has a more important role in metallization: it brings more flexibility in structural deformation.

Table 4. Bonding characters of the valence top (V.T.) and conduction bottom (C.B.) bands: (B) bonding, (AB) antibonding, and (N) nonbonding. The intraicosahedral bonding is further decomposed into three types of bonds [69]

\begin{tabular}{c|cc}
\hline \multicolumn{1}{c|}{ symmetry } & V.T. & C.B. \\
\cline { 1 - 1 } Anter- $_{1 u}(Z)$ & $A_{1 g}(\Gamma)$ \\
yntra- $p-p$ & $\mathrm{AB}$ & $\mathrm{B}$ \\
$\mathrm{yn}$ & $\mathrm{N}$ & $\mathrm{B}$ \\
in-e & $\mathrm{B}$ & $\mathrm{AB}$ \\
three- & $\mathrm{B}$ & $\mathrm{N}$ \\
center & $\mathrm{N}($ center $)$ & $\mathrm{B}$ \\
\hline
\end{tabular}
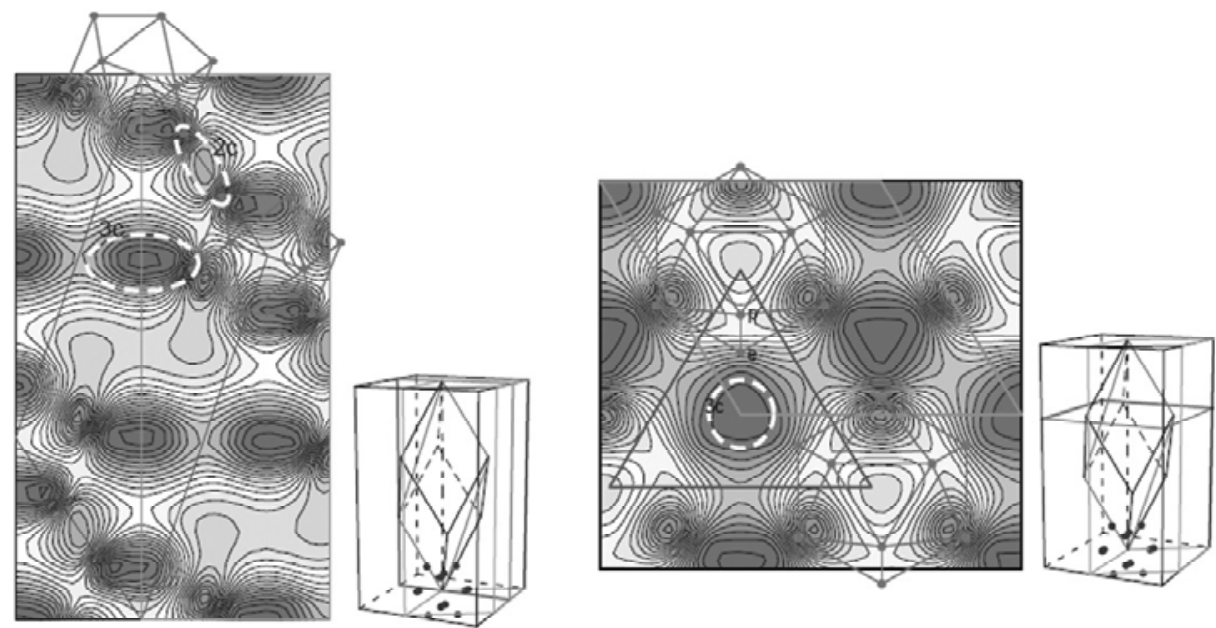

Fig. 7. Wavefunction of the bottom of conduction band, $A_{1 g}(\Gamma)$, of $\alpha$-rhombohedral boron [69].

As described above, the metal phase of $\alpha$-rhombohedral boron at high pressure actually has a mixed character of metal and semiconductor. The covalent character still remains in the six strongest intericosahedral bonds. The enhancement of the three-center bonds leads to a charge transfer from the intraicosahedral bond to the three-center bond, which brings a metallic character to $\alpha$-rhombohedral boron. At this point, a sharp contrast in the qualitative distinction between metallic and covalent bonds, i.e. a highly oriented bond (or undirectional bond) in the real space implies a semiconducting (metallic) band in the reciprocal space, is lost in boron case. Such a mixed character is, however, not specific to boron. Metals possessing such a mixed character are known, for example, in WC [97, 98] and in $\alpha-G a$ [99].

When does the metallization process begin? The fact that all the variations in the structural parameters are continuous with respect to pressure, does not necessarily infer that there is no characteristic pressure, at which something changes. Rather, our studies on $\alpha$-rhombohedral boron resolve a clear characteristic pressure around $50 \mathrm{GPa}$, at which the metallization process begins 
$[68,69]$. Here, what is meant by saying "the metallization process begins" is the situation, in which the three-center bond begins to have appreciable influence on the electronic structure, but not the gap closing. There are three pieces of the evidence for this. The first is a change in the pressure dependence of the apex angle $\partial \alpha_{\mathrm{rh}} / \partial p$ of the rhombohedral lattice. Initially, $\partial \alpha_{\mathrm{rh}} / \partial p$ of $\alpha$-rhombohedral boron is negative. Around $p=50 \mathrm{GPa}$, this decrease ceases and then $\partial \alpha_{\mathrm{rh}} / \partial p$ turns to be positive. This change is brought about by the change in the balance of the intericosahedral two-center bond and three-center bond. The three-center bond acts as a restoring force for further reducing $\alpha_{\mathrm{rh}}$. The second is the step structure in the pressure dependence of resistivity [65]. Such step structures are commonly observed in boron solids [5, 65]. These step structures used to be interpreted as a sign of phase transition [100]. However, our careful band calculations resolve that this step structure is brought about by a bowing of the conduction band minimum [69]. Even continuous change in the band structure can show a discontinuity in the electrical resistivity. The third is the softening of the librational mode around this pressure. This phonon has an interesting property of a little pressure dependence of the frequency. The mechanism will be described later in subsection Pressure dependence of the librational mode. At very high pressures more than $50 \mathrm{GPa}$, this mode exhibits a slight softening $[67,101,102]$. This infers an enhancement of the metallic character of bonding, i.e. weak angle forces.

Gap problem. A big problem of the electronic structure of boron solids is the energy gap. For $\alpha$-rhombohedral boron, there is a disagreement in the energy gap, as described in the precedent section. The discrepancy of this kind is typical for DFT calculation: DFT calculations are prone to underestimate the energy gap. Nevertheless, the semiconducting character is well reproduced by the band theory. However, for the cases of $\beta$-rhombohedral boron and boron carbides, a different class of problems arises. Even for the qualitative aspect of the energy gap, there is a serious disagreement between the theory and experiment. Standard band calculations lead to a conclusion that stoichiometric $\mathrm{B}_{105}$ and $\mathrm{B}_{13} \mathrm{C}_{2}$ are metallic, as indicated in Table 3 . This is a direct consequence of the band theory stating that the crystal with an odd number of valence electrons must be metal, the conclusion of which is independent of the calculation method.

The energy gap is also a problem for the experimental side. For $\beta$-rhombohedral boron, the energy gap is estimated at $1.56 \mathrm{eV}$, but a considerable density of gap states covers a wide range of the gaps [103]. For boron carbides, an indirect gap was once identified as $0.48 \mathrm{eV}$ by optical measurements [104]. Since then, the presence of high-density of gap states and strong excitons has been recognized [103]. According to recent experiments [103], the band gap has been modified as $2.09 \mathrm{eV}$. On the other hand, all band calculations so far published show gaps as large as $3 \mathrm{eV}[74,105-110]$. Let us look in more detail at the calculated energy gap of boron carbide. DFT band structures of boron carbides are seen in a series of papers by Kleinman's group: [106] for $\mathrm{B}_{11} \mathrm{C}(\mathrm{CBC})$ and [107] for $\mathrm{B}_{12}(\mathrm{CBC})$. LDA band calculations have shown large energy gaps for boron carbides; $2.78 \mathrm{eV}$ (indirect $F-L$ in the present notations) for $\mathrm{B}_{11} \mathrm{C}(\mathrm{CBC})[106]$ and $2.92 \mathrm{eV}$ for $\mathrm{B}_{12}(\mathrm{CBC})$ [107]. Note that the value for $\mathrm{B}_{12}(\mathrm{CBC})$ is obtained by ignoring the fact that the valence top band is partially occupied. In our calculation, the gap is $2.68 \mathrm{eV}$ for $\mathrm{B}_{12}(\mathrm{CBC})$. The fact that the calculated gaps are large itself is unusual in that LDA gap has a tendency to underestimate energy gap.

The gap problem was once discussed in terms of Jahn-Teller effects [111]. But, in the author opinion, the Jahn-Teller effect itself is too general to account for 
special features of boron solids. From a good correlation between the disagreement of the energy gap and the concentration of defects, Schmechel and Werheit have put forth an idea that the insulating properties of $\beta$-rhombohedral boron and boron carbides are due to the localization of the relevant bands by the intrinsic defects $[27,41]$. Though discussion of this issue based on DFT calculations is deferred to in subsection Cause of defects, this is the most reasonable account for the discrepancy about the gap structure. A qualitative explanation of the localization is not easy even in the present status of DFT calculations [112]. An influence of defects on the gap states for $\beta$-rhombohedral boron was examined under very restricted conditions [10]. A question as to whether the gap problem is solved by using large supercells, is a challenge of the next step in theoretical study.

Deformation potential. The pressure dependence of the energy gap $A_{g}=d E_{g} / d p$ is a measure for the stiffness of the energy gap, which is an important parameter determining the type of the phase transition. The pressure coefficient $A_{g}$ is related to the deformation potential $a_{g}$ by (1) where $B$ is bulk modulus. Usually, $A_{g}$ is negative and its absolute value is greater in insulators than in semiconductors [113 - 115]. As a consequence, for insulators, the band closure occurs at relatively low pressures.

$$
A_{g} \equiv \frac{d E_{g}}{d p}=\frac{a_{g}}{B} .
$$

For $\alpha$-rhombohedral boron, $a_{g}=3.4 \mathrm{eV}$ [69]. This is comparable to that of other IV group semiconductors $[113,114]$. The pressure coefficient of $\alpha$-rhombohedral boron, $A_{g}=-17 \mathrm{meV} / \mathrm{GPa}$, is similar to those of various semiconductors, for example, $-19 \mathrm{meV} / \mathrm{GPa}$ for $\mathrm{Si}$ and $-16 \mathrm{meV} / \mathrm{GPa}$ for $\mathrm{Ge}[116,117]$. From these slopes $A_{g}$, the gap closure would be expected to occur at about $p=100 \mathrm{GPa}$ for typical semiconductors. In reality, most tetrahedrally coordinated semiconductors are transformed to other metallic structures, such as the $\beta$-Sn structure, before the gap closure occurs $[118,119]$. Crystals with a low coordination number become unstable at high pressures, unless their bonds are very strong. Diamond is an exception. Indeed, the pressure coefficient $A_{g}$ of diamond is positive [116, 117]. This positive sign remains even at $2000 \mathrm{GPa}$. The metallization of diamond is still an active field of research $[120,121]$.

The small deformation potential $a$ along with a large $B$ makes the band closure of $\alpha$-rhombohedral boron occur at a very high pressure of about $160 \mathrm{GPa}$. The pressure coefficient $A_{g}$ for $\beta$-rhombohedral boron is $70 \mathrm{meV} / \mathrm{GPa}$ [122], which is larger than the value of $\alpha$-rhombohedral boron. This is reasonable, because $\beta$ rhombohedral boron is softer than $\alpha$-rhombohedral boron.

The significance of the deformation potential for the phase transition will be discussed in Part II of the paper. The deformation potential could also have a role in the hardness. Argument from this point of view is scarce.

Boron carbides. A difficulty in theoretical study on boron carbides is the disorders in the atom arrangement and chemical composition. In the real materials, there is no stoichiometric compound, and a variety of atom arrangements, such as $\left(\mathrm{B}_{11} \mathrm{C}\right)(\mathrm{CBC}),\left(\mathrm{B}_{11} \mathrm{C}\right)(\mathrm{BBC})$, are statistically distributed. Presently, we do not have a good model treating such complicated structure of defects. Nonetheless, the structural parameters of $\mathrm{B}_{12} \mathrm{C}_{3}$ and $\mathrm{B}_{13} \mathrm{C}_{2}$ are rather well described by DFT calculations ignoring the details of disorder [106, 107, 123, 124]. Systematic changes in the lattice parameter and $\mathrm{BC}$ bond length as a function of $\mathrm{C}$ content, 
which are found in experiment, are reproduced by simple models of the structure [125]. Bulk modulus is not sensitive to the details of the structure of boron carbides.

However, there are cases for which the property is sensitive to the defect. By using this sensitivity, a variety of defect configurations are identified by Raman spectroscopy [123] and NMR spectroscopy [108]. With the latter method, the presence of even such a structure $\left(\mathrm{B}_{10} \mathrm{C}_{2}\right)(\mathrm{BBC})$, which is otherwise difficult to identify, is suggested. A review as to what properties DFT calculations clarify about boron carbides is given by Vast et al. [126], placing emphasis on a variety of the chain configurations including vacancy. Interested readers should refer to this review. The remaining of this subsection treats the gap closure of boron carbide, which is not covered in [126].

Saying gap closure, the gap even at ambient pressure is a problem for boron carbide, as described in subsection Gap problem. There are a couple of arguments concerning this problem [11, 27, 41, 106-108, 123, 127, 128]. Band calculations based on simple structural models, such as $\left(\mathrm{B}_{11} \mathrm{C}\right)(\mathrm{CBC})$ and $\mathrm{B}_{12}(\mathrm{CBC})$, are not sufficient to determine the energy gap. In spite of this, it seems that such calculations can provide the upper bound of the gap closure. With this utility, the pressure dependence of the gap for $\mathrm{B}_{12}(\mathrm{CCC})$ and $\mathrm{B}_{12}(\mathrm{CBC})$ has been examined [124].

The results are shown in Fig. 8. In both crystals, the gap closure is as large as $600 \mathrm{GPa}$. Therefore, the gap-closing pressure would be the highest among known crystals, except diamond. This pressure is higher than the range presently accessible to experiment. This conclusion does not exclude the possibility of the occurrence of phase transition before the gap closure. So far, most of experimental results show that boron carbides undergo a transition to amorphous phase at far lower pressure than the above. Gogotsi's group reports a phase transition of boron carbide to disordered or undefined phases by static indentation technique, and the estimated pressure is about 44-49 GPa $[129,130]$. Also, in their paper they cite a transition pressure of about $20 \mathrm{GPa}$ measured by Manghnani. Pressure-induced amorphization is reported by Yan el al. [131]. In addition, dynamic indentation has been applied to see amorphization [132]. A computer simulation shows that the amorphization occurs at $6 \mathrm{GPa}$ by shock conditions [133]. Very recently, however, a new result of high-pressure experiment on boron carbide has demonstrated that the crystal structure of boron carbide is stable up to $100 \mathrm{GPa}$ under the static conditions [134]. Further study is in progress by using good-quality samples. The pressure dependence of gap, $A_{g}$, is very small, $-2 \mathrm{meV} / \mathrm{GPa}$, by averaging over all the pressure range [124]. This is particularly interesting, by considering that the value is much smaller than that of $\alpha$-rhombohedral boron $(-17 \mathrm{meV} / \mathrm{GPa})$, despite that the structure is different only in the presence of the $\mathrm{C}$ chain otherwise the same. A recently discovered high-pressure phase of boron, $\gamma$-orthorhombic boron, also has a very small value $A_{g}=-1 \mathrm{meV} / \mathrm{GPa}$ [3]. When we look at a low pressure region $(<10 \mathrm{GPa})$, the slope $\left|A_{g}\right|$ is less than $1 \mathrm{meV} / \mathrm{GPa}$, and it seems even positive for the initial slope. This fact might have significance in the transport property of boron carbides. Under high pressures, an unusual property of boron carbides is found that the electrical resistivity is increased with increasing pressure [128]. This property was once explained in terms of the small bi-polaron mechanism [11]. However, this mechanism was subjected to criticism [27]. Further study is required. 


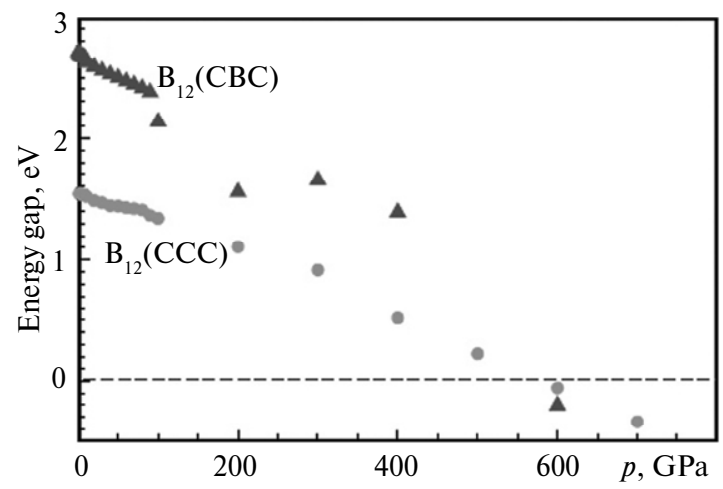

Fig. 8. Pressure dependence of the energy gap of boron carbide, $B_{12}(C C C)[124]$ and $B_{12}(C B C)$.

Ionicity. The term "ionicity" might be another important concept for understanding the physical and chemical properties of boron solids [135]. Recently, this concept attracts much attention in connection with successive discoveries of boron solids, such as $\gamma$-boron [3]. I apologize to readers for not providing deep insights into the role of ionicity in the material research, besides saying a plain thought that the ionicity is only a consequence of the structure but not the cause. I just introduce this concept through answering to a question by which innocent beginners would be embarrassed. I hope that somebody is able to develop this concept.

The issue is what the ionicity for pure boron is. Boron crystals, whatever the crystal structure is, are composed of only one species. Why does the crystal have ionicity? This question seems natural, considering the term of "homopolar semiconductors", such as $\mathrm{Si}$, where there is no dipole moment. The reason is that atoms are not simple point charge. Even the same chemical element can have different charge distributions. Only those atoms, which are equivalent by the crystal symmetry, have exactly the same charge distribution. In fact, elemental crystals can have IR-active modes (polar modes) in their phonon spectra [136, 137]. The existence of dipole moment for those elemental crystals can be described formally by a shell model [138]. Unfortunately, for numeric calculation, shell model is not too suitable to calculate IR and Raman spectra: unrealistic parameters must be used for obtaining the observed intensity [139, 140]. Adiabatic bond charge model is a more realistic model for optical spectra of semiconductors [141]. A pictorial illustration by an adiabatic bond charge model naturally leads a mechanism for why a polar mode conveys a sizable dipole moment with their motions as observed [142]. Even though now such a dynamic dipole moment can be handled by DFT calculations, usefulness of a model description is not lost.

\section{Phonon properties}

Phonon spectra of $\alpha$-rhombohedral boron. In thermodynamics, calculation of phonons is of importance for a bridge between the ground-state theory and finitetemperature theory through free energies, the feature of which is fully used in Part II of the paper. On the other hand, in the history of the boron study, phonon properties have sometimes decisive roles in our understanding of bonding nature of boron solids. For experimental data, the most updated reference is a review by Werheit [143].

The phonons of $\alpha$-rhombohedral boron have been well studied. In the early stage, phonon spectra were calculated by force-constant models. Those models include a Keating model [144], valence-force model [145], and shell model [137]. 
The most important conclusion derived from those model calculations is that the intericosahedral force constant $\left(f_{2}\right)$ is stronger than the intraicosahedral force constant $\left(f_{\text {in }}\right)[137,144-146]$,

$$
f_{2} \approx 3 f_{\text {in }}
$$

This fact is evident from a comparison of the frequencies of the highest two Raman peaks, $A_{1 g}$ and $E_{g}$ modes. This is consistent with the structural investigation that the intericosahedral bond is shorter than the intraicosahedral bond as described in subsection Icosahedron-based structure.
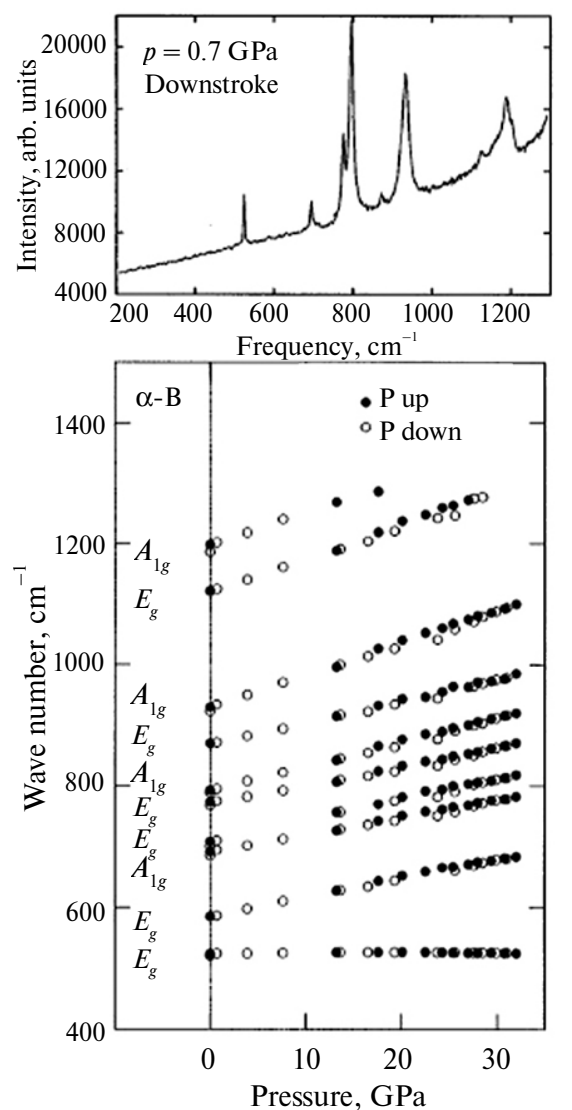

Fig. 9. Raman spectra of $\alpha$-rhombohedral boron and the pressure dependence of phonon frequencies [80].
As far as the phonon frequencies are concerned, these model calculations give good agreement with experiment. The exception is the so-called ghost peak at $527 \mathrm{~cm}^{-1}$ appearing in the Raman spectrum $[147,148]$. This band exhibits a very narrow linewidth; see Fig. 9. Indeed, the linewidth is the narrowest in the literature at room temperature (see Fig. 1 of Ref. [149]). The linewidth is even less than the resolution limit of the conventional Raman spectroscopy [80, 148]. Model calculations were unable to describe this frequency $[137,144,145]$. The origin of this ghost peak has been disclosed by DFT calculation along with high-pressure experiment [80]. Vast et al. proved that the ghost peak is due to the librational mode, that is, rotational vibration of icosahedron.

Why did the force constant models fail to calculate the librational frequency, $\omega_{l}$ ? Previous model calculations gave a low value around $170 \mathrm{~cm}^{-1}$ for $\omega_{l}$. The frequency $\omega_{l}$ of the librational mode is governed by the angle bending force, $\omega_{l}^{2} \approx$ const $f_{a}$, where $f_{a}$ is the force constant of the angle bending. Does the fact of the high frequency $527 \mathrm{~cm}^{-1}$ for the librational mode mean a large angle bending force? The answer is no. A subsequent study shows that the angle force constant is not so large but is quite normal for semiconductors [146]. The ratio of the angle force constant to the stretching force constant can be regarded as a measure of the covalency; the ratio increases as going from $\mathrm{Ge}(\mathrm{a}$ few $\%)$ to diamond $(10 \%)$. The ratio of boron is fallen in this range, that is, a few \%. The genuine reason of the high frequency is that the number of angles involved in the librational mode is too many. In the previous model calculations used only selected angles among those angles of the same order of magnitude. Therefore, if all those angles are counted correctly, even force-constant models can describe the librational mode well.

Significance of angle bending forces. Let me mention the importance of the angle forces for the mechanical stability of $\alpha$-rhombohedral boron. The author had 
previously discussed the difference between the $\alpha$ and $\beta$ phases using the constraint theory [150]. The idea of the constraint theory is that the stiffness of crystals can be expressed by the number of the nearest neighbor bonds, which is successful for the classification of the stiffness among chalcogenides and amorphous semiconductors [151]. In the $\alpha$-rhombohedral boron, $B_{12}$ units are connected to each other by a point contact, that is, a single bond, while in the $\beta$ rhombohedral boron, $\mathrm{B}_{84}$ units are connected to each other by a face contact, that is, multiple bonds (see Fig. 3). As a result, the structure of the $\alpha$ phase would be unstable for shear strains.

One shortcoming of this argument is, however, overlooking the role of angle forces. After the study by Vast et al. [80], the role of angle bending had been refocussed. Even though the angle force constants are not too large, we see that the angle forces play an essential role for $C_{44}$ component of the elastic constant [146]. This concerning is described in the second part of the paper. Therefore, the stability and stiff property of $\alpha$-rhombohedral boron largely depend on the highly oriented character of intericosahedral bonds. The stability of $\alpha$-rhombohedral boron is just because it is a semiconductor. The structure of $\alpha$-rhombohedral boron is the structure for which the bonding requirements are most satisfactory fulfilled among boron polymorphs. Any attempt to dope to $\alpha$-rhombohedral boron results in softening in phonon and elastic properties [93], which infers that the bonding strength is maximized for pure $\alpha$-rhombohedral structure.

Pressure dependence of the librational mode. In identification of the librational mode, the high pressure experiment played a role of central importance. In study by Vast, et al [80], not only one-point agreement but the whole agreement over all the range of pressure gave a strong impression, which convinced us of this identification. This is an outstanding example for illustrating the usefulness of high-pressure research. In the pressure dependence of phonon frequency, another interesting issue is that only for the librational mode the frequency is almost independent of pressure (see Fig. 9). Again, we find an extraordinary property for this mode. Usually, pressure dependence on phonon frequency comes from anharmonicity. The linewidth of phonon spectra is also originated from the anharmonicity. From this observation, we are vulnerable to interpreting that the narrow linewidth of the librational mode is due to a small anharmonicity of this mode. Interestingly, this is not true [146]. Actually, the little pressure dependence of the librational mode, which is usually lowest-lying mode, is rather a common property among those crystals having rigid units [152 - 154].

Under hydrostatic pressure, the crystal is deformed almost homogeneously. This means that the cell volume $V$ and the bond length $r$ decrease proportionally but the angle $\theta$ does not change, i.e., $\partial \theta / \partial V \approx 0$. Ignoring the numerical factor, we can decompose the pressure dependence of $\omega_{l}$ as

$$
\frac{\partial \omega_{l}}{\partial p} \propto\left[\frac{\partial f_{a}}{\partial \theta} \frac{\partial \theta}{\partial V}+\frac{\partial f_{a}}{\partial r} \frac{\partial r}{\partial V}\right] \frac{\partial V}{\partial p} .
$$

Compared with $\partial f_{a} / \partial \theta$, the nondiagonal term $\partial f_{a} / \partial r$ has a secondary effect, i.e. one order of magnitude smaller than the former [146]. Thus, the first term in the bracket in Eq. (3) would be the dominant term, if the other conditions were the same. However, for hydrostatic deformation, by the fact that $\partial \theta / \partial V \approx 0$, the pressure dependence of the librational mode is eliminated, irrespective of the magnitude of the anharmonic term $\partial f_{a} / \partial \theta$. Sometimes this geometrical effect, $\partial \theta / \partial V \approx 0$, is overlooked in the literature [155]. 
The ingenious mechanism of the narrow linewidth is rather complicated. In shortly, we can say that the decay channel of the librational mode is dominated by the difference part of two-phonon DOS, and its thermal population vanishes at temperatures less than the librational frequency. For further details of the mechanism, refer to [146], and for the implications to other crystals refer to [156].

\section{Cause of defects}

As stressed in occasion until this part, defects play crucial roles for the physical properties of boron-rich solids. For $\beta$-rhombohedral boron, because of computational difficulties, defect states used to be studied only by molecular orbital calculations $[157,158]$. The first full calculation of the crystal for defects was done by Masago et al. [46]. It is experimentally known that a specific site of boron, $\mathrm{B}(13)$, has a partial occupancy [29]. Their calculation shows that this occurs not accidentally, but occurs necessarily as the energetic reason. They resolved slight changes in the bond lengths caused by defects, which is in good agreement with experiment. It is interesting to know that even a few percent of deviations in the bond length from experiment have the meaning for identifying defect configurations.

As a matter of fact, the presence of defects was recognized for $\beta$-rhombohedral boron, even when the phase was first identified [29]. Then, further complicated types of defects were identified [30-32, 48]. Effects of such complicated defects have been studied by Widom and Mihalkovič [159]. Further studies followed [160, 161]. Now, we have confirmed that the presence of defects is essential for the boron crystal stability. Ogitsu et al. have set forth an idea that the electronic structure of $\beta$-rhombohedral boron can be characterized as a frustrate system [161]. A similar idea was once aroused by Golikova in terms of "amorphous concept" $[162,163]$. However, in the author's opinion, the present proposal of frustrate system is essentially different from the old idea of amorphous concept. The favour of boron-rich solids for defects is neither due to the nonequilibrium nature of the preparation process nor to the effect of entropy at finite temperatures. It is due to the ground-state property: it has the origin in the own bonding nature.

For boron carbide, the effect of defects is already discussed in subsection Gap problem, in connection to the energy gap. Why does boron carbide refuse possessing such a simple (and beautiful) structure as $\mathrm{B}_{12}(\mathrm{CCC})$ all about? Our calculation shows that the structure $\mathrm{B}_{12}(\mathrm{CCC})$ gives rise to a gap state. The gap state is the degenerate $\pi$ state at the center of the chain, which has a non-bonding character (see Fig. 2 of Ref. [124]). Replacement of the central C atom with a B atom in an icosahedron $B_{12}$ enhances the valence states of intraicosahedral states, eliminating the degenerate gap state.

For $\mathrm{B}_{13} \mathrm{C}_{2}$ and less $\mathrm{C}$ compounds, Balakrishnarajan et al. show that the valence top band has an antibonding character for the bond between the $\mathrm{CBC}$ chain and an equatorial B site, and thereby it is a little unstable [110]. This causes releasing of an electron from the chain bond, resulting in replacement of the $\mathrm{CBC}$ chain with CBB chain. This is why boron carbides incorporate so easily disorders. In this case also, characterization as frustrate system is appropriate.

There is a long-debated issue as to whether the chain bond is stiff or not. In terms of the bond length and phonon properties, it is indisputable that the chain bond is the strongest among the bonds of this crystal [77]. Despite, there are many observations indicating the occurrence of defects in the chain [40,164], which led some researchers to interpret it as soft bond $[127,165]$. This contradiction has not been completely resolved. However, I like to stress that even the strongest bond 
could have a soft aspect. In the linear chain, whereas the force constant for the bond stretching is by far the strongest, the restoring force against the displacement perpendicular to the bond axis is very weak, i.e. less than $10 \%$ of the bond stretching [125]. The barrier height of the $\mathrm{B}$ atom to move in the perpendicular direction is only about $100 \mathrm{meV}$, so that it is easy for the $\mathrm{B}$ atom to displace from the central position. Such a dual character of stiff and soft bond is found in $\mathrm{H}$ impurity in crystal $\mathrm{Si}$, where $\mathrm{H}$ impurity forms $\mathrm{Si}-\mathrm{H}-\mathrm{Si}$ chain bond [166]. While the bond stretching of the $\mathrm{Si}-\mathrm{H}$ bond has the largest force constant in this system, a molecular dynamics simulation shows that the $\mathrm{H}$ atom easily migrates among interstitial sites even at room temperature. In the defects in semiconductors, it is known a rather surprising feature that an impurity atom can be displaced in the direction of the strongest bond in some circumstances [167].

Examining defects in $\alpha$-rhombohedral boron is interesting, because the $\alpha$ phase is so far considered as a perfect occupancy system, but it has a critical importance for the phase stability compared to $\beta$ phase, as discussed in the second part. The first study for this subject is made by Dekura et al. [168], with a tentative conclusion that defects do not occur in $\alpha$-rhombohedral boron at such a level of concentration that thermodynamical stability is significantly influenced. Further study is in progress.

Up to this point, it is clear that $\alpha$-rhombohedral boron is exceptionally perfect among the boron polymorphs, indicating that the bonding requirement is most satisfactorily fulfilled in $\alpha$-rhombohedral boron. An old thought that the elimination of the unstable three-center bond in $\alpha$-rhombohedral boron is a driving force to form a variety of complicated polymorphs of boron, is incorrect. The disorders of the boron polymorphs other than the $\alpha$ phase are originated from their own bonding requirement.

All the precedent arguments are based on the energetics of the ground states. For finite temperatures, the effect of defects becomes more important through the entropic contribution to free energies. Naturally, boron crystals exhibit a defectrich property. For $\beta$-rhombohedral boron, many interstitial sites are found for dopant impurities [32]. This says that incorporation of impurities to $\beta$ rhombohedral boron is easy, compared with $\alpha$-rhombohedral boron. But, this easiness has another effect to cause further defects, which results in the poor controllability of the valence electrons of $\beta$-rhombohedral boron [169-171].

Бор і кристали з високим вмістом бору є твердими матеріалами, чиі унікальні властивості порівнянні з властивостями інших твердих матеріалів, таких як алмаз. Різні способи розташування ікосаедрів дають багато складних кристалічних модифікацій та їх похідних. Хоча кристали, в основному, тверді, їх механічні й хімічні властивості внутрішньо податливі. Ця піддатливість є наслідком згоди між м'якою $i$ твердою частинами структури. М'яка частина передається ікосаедричним вузлом, а тверда частина - зв'язками, щзо з'єднують ікосаедри. Дана стаття є спробою дати несуперечливий опис унікальних властивостей бору й багатих бором твердих тіл, виходячи з розрахунків електронної структури. Недавні розробки розрахунків з перших принцииів зробили важливий внесок у наме розуміння незвичайних властивостей матеріалів иього класу. Зокрема, комбінація експериментів при високих тисках $\epsilon$ успішною в приведенні переконливих свідчень для нашого розуміння й приводить до непередбачених подій, таких як відкриття надпровідності. Аналізи багатьох властивостей твердого бору говорять про необхідність обережності у визначенні впливу особливого розташування атомів та їх релаксаиії для тих складних структур, які інакще могли б створити неправильне уявлення про наші інтуїтивні інтерпретації. Особливу увагу приділено стабільності фаз і фазовим переходам при високих тисках через недавні послідовні відкриття нових твердих матеріалів, таких як ү-орторомбічний бор $i$ алмазоподібна сполука $B C_{5}$. У першій частині цього огляду описано основний стан бору й 
збагачених бором кристалів. Обговорено ширину забороненої зони, власні дефекти й властивості фононів.

Ключові слова: ромбоедричний бор, кристали з високим вмістом бору, розрахунки з перших принципів, структура, що базується на ікосаедрах, власні дефекти, електронна структура.

Бор и кристаллы с высоким содержанием бора являются твердыми материалами, чви уникальные свойства сравнимы со свойствами других твердых материалов, таких как алмаз. Различные способы расположения икосаэдров дают много сложных кристаллических модификаций и их производных. Хотя кристалль, в основном, твердые, их механические и химические свойства внутренне податливы. Эта податливость является следствием согласия между мягкой и твердой частями структуры. Мягкая часть передается икосаэдральным узлом, а твердая часть связями, соединяющими икосаэдры. Данная статья является попыткой дать непротиворечивое описание уникальных свойств бора и богатых бором твердых тел, исходя из расчетов электронной структуры. Недавние разработки расчетов из первых принципов внесли важный вклад в наме понимание необычных свойств материалов этого класса. В частности, комбинация экспериментов при высоких давлениях является успешной в приведении убедительных свидетельств для намего понимания и приводит $\kappa$ непредвиденным событиям, таким как открытие сверхпроводимости. Анализы многих свойств твердого бора говорят о необходимости осторожности в определении влияния особого расположения атомов и их релаксации для тех сложных структур, которые иначе могли бы создать ложное представление о наших интуитивных интерпретациях. Особое внимание уделено стабильности фаз и фазовым переходам при высоких давлениях из-за недавних последовательных открытий новых твердых материалов, таких как $\gamma$ орторомбический бор и алмазоподобное соединение $B C_{5}$. B первой части этого обзора описывается основное состояние бора и обогащенных бором кристаллов. Обсуждаются ширина запрещённой зоны, собственные дефекты, и свойства фононов.

Ключевые слова: ромбоэдрический бор, кристаллы с высоким содержанием бора, расчеты из первых приниипов; структура, основанная на икосаэдрах; собственные дефекты, электронная структура.

1. Solozhenko V. L., Kurakevych O. O., Andrault D. et al. Ultimate metastable solubility of boron in diamond: synthesis of superhard diamond-like $\mathrm{BC}_{5} / /$ Phys. Rev. Lett. — 2009. - 102. P. 015506 (4 p.), (Erratum), 2009. - 102. - P. 179901 (1 p.).

2. Solozhenko V. L., Kurakevych O. O., Oganov A. R. On the hardness of a new boron phase, orthorhombic $\gamma-\mathrm{B}_{28} / /$ J. Superhard Materials. — 2008. - 30. - P. 428 - 429.

3. Oganov A. R., Chen J., Gatti C. et al. Ionic high-pressure form of elemental boron // Nature. - 2009. - 457. - P. 863-867.

4. Zarechnaya E. Y., Dubrovinsky L., Dubrovinskaia N. et al. Synthesis of an orthorhombic high pressure boron phase // Sci. Tech. Advanced Materials. — 2009. - 9. - P. 044209 (4 p.).

5. Eremets M. I., Struzhkin V. V., Mao H., Hemley R. J. Superconductivity in Boron // Science. - 2001. - 293. - P. 272-274.

6. Ekimov E. A., V Sidorov. A., Bauer E. D. et al. Superconductivity in diamond // Nature. 2004. - 428. - p. 542-545.

7. Bustarret E., Marcenat C., Achatz P. J. et al. Superconductivity in doped cubic silicon // Ibid. - 2006. - 444. - P. 465-468.

8. Takano Y., Nagao M., Sakaguchi I. et al. Superconductivity in diamond thin films well above liquid helium temperature // Appl. Phys. Lett. - 2004. - 85. - P. 2851-2853.

9. Ren Z. A., Kato J., Muranaka T. et al. Superconductivity in boron-doped SiC // J. Phys. Soc. Jpn. - 2007. - 76. - P. 103710 (4 p.).

10. Shirai K., Dekura H., Masago A. Superconductivity research on boron solids and an efficient doping method // J. Phys.: Conf. Ser. — 2009. — 176. — P. 012001 (18 p.).

11. Wood C., Emin D. Conduction mechanism in boron carbide // Phys. Rev. B. - 1984. — 29. - P. 4582- 4587.

12. Emin D. Icosahedral Boron-Rich Solids // Phys. Today. - 1987. - 40. - P. 55-62.

13. Emin $D$. Enhanced seebeck coefficient from carrier-induced vibrational softening // Phys. Rev. B. - 1999. - 59. - P. 6205-6210. 
14. Aselage T. L., Emin D., McCready S. S. Conductivities and seebeck coefficients of boron carbides: Softening bipolaron hopping // Ibid. — 2001. — 64. — P. 054302 (8 p.).

15. Nielsen O. H., Martin R. M. Quantum-mechanical theory of stress and force // Ibid. -1985 . - 32. - P. 3780-3791.

16. Galli G., Gygi F., Catellani A. Quantum mechanical simulations of microfracture in a complex material // Phys. Rev. Lett. — 1999. — 82. — P. 3476-3479.

17. Roundy D., Cohen M. L. Ideal strength of diamond, Si, and Ge// Phys. Rev. B. - 2001. 64. - P. 212103 (3 p.).

18. Krenn C. R., Roundy D., Cohen M. L. et al. Connecting atomistic and experimental estimates of ideal strength // Ibid. - 2002. - 65. - P. 134111 (4 p.).

19. Gao F., He J., Wu E. et al. Hardness of covalent crystals // Phys. Rev. Lett. - 2003. — 91. - P. 015502 (4 p.) (2003)

20. Šminunek A., Vacktáŕ J. Hardness of covalent and ionic crystals: first-principle calculations // Ibid. - 2006. - 96. - P. 085501.

21. Werheit H., Schmechel R. Landolt-Börnstein, Numerical data and functional relationships in science and technology, New Series III/41c, Berlin: Springer-Verlag, 1998.

22. Werheit H. Landolt-Börnstein, Numerical data and functional relationships in science and technology, New Series III/41d. - Berlin: Springer-Verlag, 2000.

23. Greenwood N. N. Boron // Comprehensive inorganic chemistry / Eds. J. C. Bailar, H. J. Emelreus, S. R Nyholm., A. F. Trotman-Dickenson. - Oxford: Pergamon, 1973. — Ch. 11.

24. The Chemistry of boron and its compounds / Ed. E. L. Mueterties. - New York: Wiley, 1967.

25. Fundamentals and applications of boron, borides, and related materials / Eds. The organizing committee of 16th Int. Conf. of Boron Borides and Related Materials. - Tokyo: CMC Pub., 2008 (in Japanese).

26. Oganov A. R. Solozhenko V. L. Boron: a hunt for superhard polymorphs // J. Superhard Materials. - 2009. - 31. - P. 285-291.

27. Werheit $H$. Present knowledge of electronic properties and charge transport of icosahedral boron-rich solids // J. Phys.: Conf. Ser. — 2009. — 176. - P. 012019 (11 p.).

28. Hughes R. E., Kennard C. H. L., Sullenger D. B. et al. The structure of $\beta$-rhombohedral boron // J. Amer. Chem. Soc. - 1963. - 85. - P. 361-362.

29. Hoard J. L., Sullenger D. B., Kennard G. H. L., Hughes R. E. The structure analysis of $\beta$ rhombohedral boron // J. Solid State Chem. - 1970. - 1. - P. 268-277.

30. Callmer B. An accurate refinement of the $\beta$-rhombohedral boron structure // Acta Cryst. B. - 1977. - 33. - P. 1951-1954.

31. Slack G. A., Hejna C. I., Kasper J. S. The crystal structure and density of $\beta$-rhombohedral boron // J. Solid State Chem. - 988. - 76. - P. 52-63.

32. Lundström T. The structure and bonding of solid solutions of transition and $p$-elements in $\beta$ rhombohedral boron // AIP Conf. Proc. - 1986. - 140. - P. 19-30.

33. Clark H. K. Hoard J. L. The crystal structure of boron carbide // J. Am. Chem. Soc. - 1943. -65. - P. 2115-2119.

34. Hoard J. H., Hughes R. E. Elemental boron and compounds of high boron content: structure, properties, and polymorphism // The chemistry of boron and its compounds / Ed. E. L. Mueterties. - New York: Wiley, 1967. - Ch. 2.

35. Larson A. C. Comments concerning the crystal structure of $\mathrm{B}_{4} \mathrm{C} / /$ AIP Conf. Proc. -1986. - 140. - P. 109-113.

36. Kirfel A., Gupta A., Will G. The nature of the chemical bonding in boron carbide $\mathrm{B}_{12} \mathrm{C}_{2}$. I. Structural refinement // Acta Crystallogr. B. - 1979. - 35. - P. 1052-1059.

37. Duncan T. M. The distribution of carbon in boron carbide: a carbon-13 nuclear magnetic resonance study // J. Am. Chem. Soc. - 1984. - 106. - P. 2270-2275.

38. Morozsin B., Mullendore A. W., Emin D., Slack G. Rhombohedral crystal structure of compounds containing boron-rich icosahedra // AIP Conf. Proc. - 1986. - 140. - P. 70 - 86.

39. Aselage T. L. Emin D. Structural model of the boron carbide solid solution // AIP Conf. Proc. - 1991. - 231. - P. 177-185.

40. Kwei G. H., Morosin B. Structures of the boron-rich boron carbides from neutron powder diffraction: implications for the nature of the inter-icosahedral chains // J. Phys. Chem. 1996. - 100. - P. 8031-8039.

41. Schmechel R., Werheit $H$. Correlation between structural defects and electronic properties of icosahedral boron-rich solids // J. Phys.: Condens. Matter. - 1999. — 11. - P. 6803 -6813.

42. Gosset D., Colin M. Boron carbides of various compositions: an improved method for X-rays characterisation // J. Nucl. Mater. — 1991. — 183. - P. 161-173. 
43. Schwetz K. A., Karduck P. Investigations in the boron-carbon system with the aid of electron probe microanalysis // AIP Conf. Proc. - 1991. — 231. - P. 405-413.

44. Werheit H., Leithe-Jasper A., Tanaka T. et al. Some properties of single-crystal boron carbide // J. Solid State Chem. — 2004. - 177. — P. 575.

45. Decker B. F., Kasper J. S. The crystal structure of a simple rhombohedral form of boron // Acta Cryst. - 1959. - 12. - P. 503-506.

46. Masago A., Shirai K., Katayama-Yoshida H. Crystal stabilities of $\alpha$ - and $\beta$-borons // Phys. Rev. B. - 2006. - 73. - P. 104102 (10 p.).

47. Zarechnaya E. Y., Dubrovinsky L., Dubrovinskaia N. et al. Superhard semiconducting optically transparent high pressure phase of boron // Phys. Rev. Lett. - 2009. - 102. P. 185501 (4 p.).

48. Slack G. A., D. Oliver W., Horn F. H. Thermal conductivity of boron and some boron compounds // Phys. Rev. B. - 1971. - 4. - P. 1714-1720.

49. Slack G. A. Thermal conductivity of elements with complex lattices: B, P, S // Phys. Rev. 1965. - 139. - P. A507-A515.

50. Bogdanov V. J., Vekilov Yu. Ch., Tsagareishvili G. V. Analysis of debyetemperatures of boron from its thermal and elastic properties // Bor, poluchenie, structura i svojstva (Boron, Production, Structure and Properties): Proc. 4th Int. Conf. on Boron, Tbilisi, 1972. - Tbilisi: Izd. Mecniereba, 1974. - P. 33-36.

51. Nelmes R. J., Loveday J. S., Allan D. R. et al. Neutron and X-ray-diffraction measurements of the bulk modulus of boron // Phys. Rev. B. - 1993. - 47. — P. 7668 - 7673.

52. Sanz D. N., Loubeyre P., Mezouar M. Equation of state and pressure-induced amorphization of $\beta$-boron from X-ray measurements up to $100 \mathrm{GPa} / /$ Phys. Rev. Lett. — 2002. — 89. P. 245501 (4 p.).

53. Ma Y., Prewitt C. T., Zou G. et al. High-pressure high-temperature X-ray diffraction of $\beta$ boron to $30 \mathrm{GPa} / /$ Phys. Rev. B. - 2003. - 67. - P. 174116 (6 p.).

54. Wallace $D$. C. Statistical physics of crystals and liquids, a guide to highly accurate equations of state. - Singapore: World Scientific Pub., 2002.

55. Laubengayer A. W., Hurd D. T., Newkirk A. E., Hoard J. L. Boron. I. Preparation and properties of pure crystalline boron // J. Am. Chem. Soc. — 1943. - 65. - P. 1924-1931.

56. Amberger E., Druminski M., Ploog K. Das B-C-System im Kinetischen Bildungsbereich: Pyrolytische Bildung Kohlenstroffreicher B-C Phasen // J. Less-Common Metals. — 1971. - 23. - P. 21-52.

57. Will G., Kossobutzki K. H. X-ray diffraction analysis of $\mathrm{B}_{50} \mathrm{C}_{2}$ and $\mathrm{B}_{50} \mathrm{~N}_{2}$ crystallizing in the "tetragonal" boron lattice // Ibid. - 1976. - 47. - P. 33-38.

58. Morrison I., Bylander D. M., Kleinman L. Computational study of tetragonal $\mathrm{B}_{50} \mathrm{~N}_{2} / /$ Phys. Rev. B. - 1992. - 45. - P. 10872-10875.

59. Lee S., Bylander D. M., Kim W., Kleinman L. Computational search for the real tetragonal B $_{50} / /$ Phys. Rev. B. - 1992. - 45. - P. 3248-3251.

60. Hayami W., Otani S. Effect of surface energy on the growth of boron nanocrystals // J. Phys.: Conf. Ser. - 2009. - 176. - P. 012017 (7 p.).

61. Will G. Crystal structure analysis of $\mathrm{AlB}_{10}$ by the convolution molecule method // Acta Crystallogr. - 1967. - 23. - P. 1071-1079.

62. Higashi I., Sakurai T., Atoda T. Crystal structure of $\alpha-\mathrm{AlB}_{12} / /$ J. Solid State Chem. -1977. - 20. - P. 67-77.

63. Higashi I. Aluminum distribution in the boron framework of $\gamma-\mathrm{AlB}_{12} / / \mathrm{Ibid}$. - 1983. - 47. - P. 333-349.

64. Emin D. Electronic and vibrational hopping transport in boron carbides // AIP Conf. Proc. 1991. - 231. - P. 65-76.

65. Kaneshige M., Shimizu K., Hyodo H., Kimura K. Measurement of the electrical resistance in $\alpha$-boron under high pressure // Proc. 48th High-Pressure Conference of Japan. - Kurayoshi, Japan: Jpn. Soc. High Pressure Sci. Technol., 2007, 1 C06.

66. Shimizu K., Kaneshige M., Hashimoto Y. et al. Superconductivity in $\alpha$-boron at mbar pressure // Physica C, available online Nov. 13, 2009.

67. Mori Y., Fujii Y., Hyodo H. et al. X-ray diffraction study of $\alpha$-boron up to $200 \mathrm{GPa} / /$ Proc. 13th Int. Conf. "High Pressure Semiconductor Physics". - Fortaleza, Brazil, 2008.

68. Shirai K., Dekura H., Mori Y. et al. Structural study of $\alpha$-boron at high pressure, submitted to Phys. Rev. B. 
69. Shirai K., Dekura H., Yanase A. Electronic structure and electrical resistivity of $\alpha$-boron under high pressure // J. Phys. Soc. Jpn. — 2009. — 78. - P. 084714 (10 p.).

70. Pauling L. The Nature of the chemical bond, third edition. - New York: Cornell Univ. Press, 1960.

71. Longuet-Higgins H. C. The structures of electron-deficient molecules // Quart. Rev. Chem. Soc. - 1957. - 11. - P. $121-133$.

72. Longuet-Higgins H. C., de V. Roberts, $M$. The electronic structure of an icosahedron of boron atoms // Proc. Roy. Soc. A. - 1955. - 230. - P. 110-119.

73. Perrot F. First approach to the band structure of $\alpha$-rhombohedral boron // Phys. Rev. B. 1981. - 23. - P. 2004-2010.

74. Bullett D. B. Structure and bonding in crystalline boron and $\mathrm{B}_{12} \mathrm{C}_{3} / /$ J. Phys. C: Solid State Phys. - 1982. - 15. - P. 415-426.

75. Lee S., Bylander D. ., Kleinman L. Bands and bonds of $\mathrm{B}_{12} / /$ Phys. Rev. B. - 1990. - 42. - P. 1316-1320.

76. Gunji S., Kamimura H., Nakayama T. Electronic structures of newly predicted intercalation compounds "Lithium intercalated $\alpha$-boron" // J. Phys. Soc. Jpn. - 1993. - 62. — P. 2408-2418.

77. Shirai K., Emura S. Lattice vibrations and the bonding nature of boron carbide // J. Phys.: Condens. Matter. - 1996. - 50. - P. 10919-10929.

78. Switendick A. C. The electronic structure of icosahedral boron cluster // Physics and Chemistry of Finite Systems: From Clusters to Crystals, Netherlands: Kluwer Academic Pub., 1992. - Vol. I. - P. 683-690.

79. Shirai K., Nakamatsu H. Cluster calculation of the electronic structure of icosahedral boron // JJAP Series. - 1994. - 10. - P. 70-71.

80. Vast V., Baroni S., Zerah G. et al. Lattice dynamics of icosahedral $\alpha$-boron under pressure // Phys. Rev. Lett. - 1997. - 78. - P. 693-696.

81. Zhao J., J. Lu P. Pressure-induced metallization in solid boron // Phys. Rev. B. - 2002. 66. - P. 092101 (4 p.)

82. Vast $N$. examined the effect of core electrons by comparing all-electron calculations, with finding no appreciable effect (private communication).

83. Switendick A. C., Morosin B. Electronic charge density and bonding in $\alpha$-boron: An experimental-theoretical comparison // AIP Conf. Proc. - 1991. — 231. - P. 205-211.

84. Fujimori M., Nakata T., Nakayama T. et al. Peculiar covalent bonds in $\alpha$-rhombohedral boron // Phys. Rev. Lett. — 1999. — 82. — P. 4452 - 4455.

85. Hosoi S., Kim H., Nagata T. et al. Electron Density distributions in derivative crystals of $\alpha$ rhombohedral boron // J. Phys. Soc. Jpn. - 2007. - 76. - P. 044602 (8 p.).

86. Schlüter M., Sham L. J. Density-functional theory of the band gap // Density functional theory of many-fermion systems, Adv. in Quantum Chemistry / Ed. S. B. Trickey. - New York: Academic, 1990. - Vol. 21. — P. 97-112.

87. Jones $R$. O., Gunnarsson $O$. The density functional formalism, its applications, and prospects // Rev. Mod. Phys. - 1989. - 61. - P. 689-746.

88. Horn F. H. Some electrical and optical properties of simple rhombohedral boron // J. Appl. Phys. - 1959. - 30. - P. 1611-1612.

89. Golikova O. A. Electrical properties of $\alpha$-rhombohedral boron // Sov. Phys. Semicond. 1979. - 13. - P. 486- 487.

90. Golikova O. A., Solov'ev N. E., Ugai Ya.A. and Feigelmann V. A. Some electrical properties of $\alpha$-rhombohedral boron // J. Less Common Met. — 1982. — 82. — P. 362-362.

91. Werheit H. Landolt-Börnstein, Numerical data and functional relationships in science and technology, New Series III/17e. — Berlin: Springer-Verlag, 1983.

92. Terauchi M., Kawamata Y., Tanaka M. et al. Electron energy-loss spectroscopy study of the electronic structure of $\alpha$-rhombohedral boron // J. Solid State Chem. — 1997. — 133. P. $156-159$.

93. Dekura H. Dr. Thesis. - Osaka University, 2010.

94. Dekura H., Shirai K., Katayama-Yoshida H. Valence control and metallization of boron by electronic doping // Physica B. - 2007. - 401-402. - P. 702-705.

95. Dekura H., Shirai K., Yanase A. Possibility of imperfections in $\alpha$-boron // J. Phys.: Conf. Ser. - 2009. - 176. - P. 012004 (7 p.).

96. Yin M. T., Cohen M. L. Will diamond transform under megabar pressures? // Phys. Rev. Lett. - 1983. - 50. - P. 2006-2009. 
97. Mattheiss L. F., Hamann D. R. Bulk and surface electronic structure of hexagonal WC // Phys. Rev. B. - 1984. - 30. - P. 1731-1738.

98. Liu A. Y., Wentzcovitch R. M., Cohen M. L. Structural and electronic properties of WC // Ibid. — 1988. - 38. - P. 9483-9489.

99. Bernasconi M., G Chiarotti. L., Tosatti E. Ab Initio calculations of structural and electronic properties of gallium solid-state phases // Ibid. - 1995. - 52. - P. 9988 - 9998.

100. Häussermann U., Simak S. I., Ahuja R., Johansson B. Metal-nonmetal transition in the boron group elements // Phys. Rev. Lett. - 2003. - 90. - P. 065701.

101. Kaneshige M., Hirayama S., Yabuuchi T. et al. Measurement of electrical resistance and raman spectrum of $\alpha$-boron under high pressure // J. Phys. Soc. Jpn., Suppl. A. — 2007. 76. - P. $19-20$.

102. Polian A., Chervin J. C., Munsch P., Gauthier M. $\alpha$-boron at very high pressure: structural and vibrational properties // J. Phys: Conf. Ser. - 2008. - 121. - P. 042017 (4 p.).

103. Werheit H. On excitons and other gap states in boron carbide // J. Phys.: Condens. Matter. - 2006. - 18. - p. 10655-10662.

104. Werheit H., Binnenbruck H., Hausen A. Optical properties of boron carbide and comparison with $\beta$-rhombohedral boron // Phys. Stat. Sol. B. — 1971. — 47. — P. 153-158.

105. Armstrong D. R., Balland J., Pukins P. G. et al. The nature of the chemical bonding in boron carbide. IV. Electronic band structure of boron carbide, $\mathrm{B}_{12} \mathrm{C}_{2}$, and three models of the structure $\mathrm{B}_{12} \mathrm{C}_{3} / /$ Acta Crystallogr. B. - 1983. - 39. - P. 324-329.

106. Bylander D. M., Kleinman L., Lee S. Self-consistent calculations of the energy bands and bonding properties of $\mathrm{B}_{12} \mathrm{C}_{3} / /$ Phys. Rev. B. - 1990. - 42. - P. 1394-1403.

107. Bylander D. M., Kleinman L. Structure of $\mathrm{B}_{12} \mathrm{C}_{3} / /$ Ibid. - 1991. - 43. - P. 1487-1491.

108. Mauri F., Vast N., Pickard C. H. Atomic structure of icosahedral $\mathrm{B}_{4} \mathrm{C}$ boron carbide from a first- principles analysis of NMR spectra // Phys. Rev. Lett. — 2001. — 87. - P. 085506 (4 p.).

109. Saal J. E., Shang S., Liu Z.-K. The structural evolution of boron carbide via ab initio calculations // Appl. Phys. Lett. - 2007. - 91. - P. 231915 (3 p.).

110. Balakrishnarajan M. M., P Pancharatna. D., Hoffmann R. Structure and bonding in boron carbides: the invincibility of imperfections // New J. Chem. - 2007. - 31. - P. 473 - 485.

111. Franz R., Werheit $H$. Influence of the Jahn-Teller effect on the electronic band structure of boron-rich solids containing $B_{12}$ icosahedra // AIP Conf. Proc. - 1991. — 231. - P. 29-36.

112. Resta $R$. Why are insulators insulating and metals conducting? // J. Phys.: Condens. Matter. - 2002. - 14. - P. R625-R656.

113. Y P. Y., Cardona M. Fundamentals of semiconductors. - Berlin: Springer-Verlag, 1996. $-617 \mathrm{p}$.

114. Blacha A., Presting H., Cardona M. Deformation potentials of $k=0$ states of tetrahedral semiconductors // Phys. Stat. Sol. B. - 1984. - 126. - P. 11-36.

115. Rodriguez C. O., Peltzer E. L., Blanca Y., Cappannini O. M. Pressure dependence of energy gaps within local density functional formalism // Solid State Commun. - 1985. — 56. P. $575-579$.

116. Wei S.-H., Zunger A. Predicted Band-gap pressure coefficients of all diamond and zincblende semiconductors: Chemical trends // Phys. Rev. B. - 1999. — 60. — P. 5404 - 5411.

117. Camp P. E. V., Doren V. E. V., Devreese J. T. First-Principles calculation of the pressure coefficient of the indirect band gap and of the charge density of $\mathrm{C}$ and $\mathrm{Si} / / \mathrm{Ibid}$. - 1986. 34. - P. 1314-1316.

118. Yin M. T., Cohen M. L. Microscopic theory of the phase transformation and lattice dynamics of Si // Phys. Rev. Lett. - 1980. — 45. - P. 1004-1007.

119. Froyen S., Cohen M. L. High pressure phase of III-V semiconductors: A microscopic theory // Solid State Commun. - 1982. - 43. - P. 447-450.

120. Yin M. T. Si-III (BC-8) Crystal phase of Si and C: structural properties, phase stabilities, and phase transitions // Phys. Rev. B. - 1984. - 30. - P. 1773-1776.

121. Correa A. A., Bonev S. A., Galli G. Carbon under extreme conditions: Phase boundaries and electronic properties from first-principles theory // Proc. Natl. Acad. Sci. — 2006. — 103. P. $1204-1208$.

122. Adirovich E. J., Abdullaev Ja. S., Guljamov K. V. et al. Effect of high hydrostatic pressures on photoelectric properties of boron crystals // Bor, poluchenie, structura i svojstva (Boron, Production, Structure and Properties): Proc. 4th Int. Conf. on Boron, Tbilisi, 1972. - Tbilisi: Izd. Mecniereba, 1974. - p. 73-81.

123. Lazzari R., Vast V., Besson J. M. et al. Atomic structure and vibrational properties of icosahedral $\mathrm{B}_{4} \mathrm{C}$ boron carbide // Phys. Rev. Lett. - 1999. - 83. - P. 3230-3233. 
124. Dekura H., Shirai K., Yanase A. Metallicity of boron carbides at high pressure // J. Phys.: Conf. Ser. - 215. — 2010. — P. 012117 (6 p.).

125. Shirai K., Katayama-Yoshida $H$. Crystal stability of boron carbide $\mathrm{B}_{12}(\mathrm{CBC}) / /$ Proc. 25 th Int. Conf. Phys. Semicond. — Osaka: Springer, 2000. — P. 1673 - 1674.

126. Vast N., Sjakste J., Betranhandy E. Boron carbides from first-principles // J. Phys.: Conf. Ser. - 2009. - 176. - P. 012002 (18 p.).

127. Emin D. Structure and single-phase regime of boron carbides // Phys. Rev. B. - 1988. 38. - P. 6041- 6055 .

128. Samara G. A., Tardy H. L., Venturini E. L. et al. AC Hopping conductivities, dielectric constants, and reflectivities of boron carbides // Ibid. - 1993. - 48. - P. 1468-1476.

129. Domnich V., Gogotsi Y., Trenary M., Tanaka T. Nanoindentation and Raman spectroscopy studies of boron carbide single crystals // Appl. Phys. Lett. — 2002. - 81. - P. 3783 - 3785.

130. Ge D., Domnich V., Juliano T. et al. Structural damage in boron carbide under contact loading // Acta Mat. — 2004. - 52. — P. 3921-3927.

131. Yan X. Q., Li W. J., Goto T., Chen M. W. Raman spectroscopy of pressure-induced amorphous boron carbide // Appl. Phys. Lett. — 2006. - 88. - P. 131905 (3 p.).

132. Ghosh D., Subhash G., Lee C. H., Yap Y. K. Strain-induced formation of carbon and boron clusters in boron carbide during dynamic indentation // Ibid. — 2007. — 91. - P. 061910 (3 p.).

133 Fanchini G., McCauley J. W., Chhowalla M. Behavior of disordered boron carbide under stress // Phys. Rev. Lett. — 2006. — 97. — P. 035502 (4 p.).

134. Fujii T., Mori Y., Hyodo H., Kimura K. X-ray diffraction study of $\mathrm{B}_{4} \mathrm{C}$ under high pressure // J. Phys.: Conf. Ser. - 215. - 2010. - P. 012011 (4 p.).

135. He J., Wu E., Wang H. et al. Ionicities of boron-boron bonds in $\mathrm{B}_{12}$ icosahedra // Phys. Rev. Lett. - 2005. - 94. - P. 015504 (4 p.).

136. Zallen R. Symmetry and reststrahlen in elemental crystals // Phys. Rev. B. - 1968. — 173. - P. 824-832.

137. Shirai K., Gonda S. Polar vibrations and the effective charges of the icosahedral boron solid // J. Phys. Chem. Solids. - 1996. - 57. - P. 109-123.

138. King-Smith R. D., Vanderbilt D. Theory of polarization of crystalline solids // Phys. Rev. B. 1993. - 47. - P. 1651-1654; Resta R. Macroscopic polarization in crystalline dielectrics: The geometric phase approach // Rev. Mod. Phys. — 1994. - 68. — P. 899 -915.

139. Weber $W$. Adiabatic bond charge model for the phonons in diamond, $\mathrm{Si}, \mathrm{Ge}$, and $\alpha-\mathrm{Sn} / /$ Phys. Rev. B. - 1977. - 15. - P. 4789-4803.

140. Go S., Bilz H., Cardona M. Bond charge, bond polarizability, and phonon spectra in semiconductors // Phys. Rev. Lett. - 1975. - 34. - P. 580-583.

141. Shirai K., Gonda S. The dynamic effective charges of icosahedral boron by the bond-charge model // Physica B. - 1996. - 219-220. - P. 336-338.

142. Shirai $K$. Central and Non-central forces on the lattice dynamics of boron-rich solids: bonding nature of icosahedral boron solids // J. Solid State Chem. — 1997. — 133. P. $215-223$.

143. Werheit H., Filipov V., Schwarz U. et al. Raman effect in icosahedral boron-rich solids // Sci. Technol. Adv. Mater. - in press.

144. Weber W., Thorpe M. F. Vibrations in icosahedral boron molecules and in elemental boron solids // J. Phys. Chem. Solids. — 1975. — 36. — P. 967-974.

145. Beckel C. L., Yousaf M., Fuka M. Z. et al. Lattice vibrations of the icosahedral solid $\alpha$-boron // Phys. Rev. B. - 1991. — 44. - P. 2535-2552.

146. Shirai K., Katayama-Yoshida $H$. The narrow raman linewidth of a vibrational mode of $\alpha$ rhombohedral boron and its anharmonic effects // J. Phys. Soc. Jpn. — 1998. — 67. P. 3801-3808.

147. Richter $W$., Ploog K. Raman-active phonons in $\alpha$-boron // Phys. Stat. Sol. B. - 1975. 68. - P. 201-205.

148. Tallant D. R., Aselage T. L., Campbell A. N., Emin D. Boron carbide structure by raman spectroscopy // Phys. Rev. B. - 1989. - 40. - P. 5649-5656.

149. Shirai K., Dekura H., Ishisada J., Katayama-Yoshida H. Lifetime and anharmonicity of local modes in semiconductors // MRS Fall Meeting. - Boston, 2009, CC6.3. - in press.

150. Shirai $K$. The elastic properties and the mechanical stability of icosahedral boron crystals // Phys. Rev. B. - 1997. - 55. - P. 12235-12243.

151. Thorpe M. F. Bulk and surface floppy modes // J. Non-Cryst. Solids. — 1995. - 182. P. $135-142$. 
152. Mitani T., Naitou T., Matsuishi K. et al. Raman scattering in $\mathrm{CdGa}_{4} \mathrm{Se}_{4}$ under pressure // Phys. Stat. Sol. B. - 2003. - 235. - P. 321-325.

153. Kume T., Fukushima T., Sasaki S. et al. Raman study of semiconductor clathrates under high pressure // Ibid. - 2007. - 244. - P. 352-356.

154. Kontos A. G., Staurou E., Malamos $V$. et al. High pressure raman study of $\mathrm{DyPO}_{4}$ at room and low temperatures // Ibid. - 2007 - 244. - P. 386-391.

155. Shirai K., Katayama-Yoshida H. Effects of the geometries of boron-rich crystals on the lattice dynamics // J. Solid State Chem. - 2000. - 154. - P. $20-25$.

156. Shirai K., Katayama-Yoshida $H$. Anharmonicities in optical spectra of $\alpha$-rhombohedral boron // Physica B. - 1999. - 263-264. - P. 791-794.

157. Fujimori M., Kimura K. Ground and excited states of an icosahedral $\mathrm{B}_{12} \mathrm{H}_{12}$ cluster simulating the $B_{12}$ cluster in $\beta$-rhombohedral boron // J. Solid State Chem. — 1997. — 133. - P. 178-181.

158. Takeda M., Hori A., Yamashida H., Kimura K. Possibility of semiconducting quasicrystal in boron-rich solids // Mater. Tran., JIM. - 1993. - 34. - P. 128-134.

159. Widom M., Mihalkovič M. Symmetry-broken crystal structure of elemental boron at low temperature // Phys. Rev. B. - 2008. - 77. - P. 064113 (8 p.).

160. van Setten M. J., Uijttewaal M. A., de Wijs G. A., de Groot A. Thermodynamic stability of boron: The role of defects and zero point motion // J. Am. Chem. Soc. - 2007. - 129. P. $2458-2465$.

161. Ogitsu T., Gygi F., Reed J. et al. Imperfect crystal and unusual semiconductor: Boron, a frustrated element // Ibid. - 2009. - 131. - P. 1903-1909.

162. Golikova O. A. Boron and boron-based semiconductors // Phys. Status Solidi A. - 1979. 51. - P. $11-40$.

163. Golikova O. A. Boron-rich borides as the models of amorphous semiconductors // AIP Conf. Proc. - 1991. - 231. - P. 108-116.

164. Yakel H. L. The crystal structure of a boron-rich boron carbide // Acta Crystallogr. B. 1975. - 31. - P. 1797-1806.

165. Aselage T. L., Tallant D.R., Emin D. Isotope dependencies of raman spectra of $\mathrm{B}_{12} \mathrm{As}_{2}$, $\mathrm{B}_{12} \mathrm{P}_{3}, \mathrm{~B}_{12} \mathrm{O}_{2}$, and $\mathrm{B}_{12+2} \mathrm{C}_{3-x}$ : Bonding of intericosahedral chains // Phys. Rev. B. - 1997. 56. - P. $3122-3129$.

166. Shirai K., Hamada I., Katayama-Yoshida H. Vibration problem of h in silicon // Physica B. - 2006. - 376-377. - P. 41-44.

167. Chadi D. J., Chang K. J. Metastability of the isolated arsenic-antisite defect in GaAs // Phys. Rev. Lett. - 1988. - 60. - P. 2187-2190; Chadi D. J., Chang K. J. Theory of the atomic and electronic structure of DX centers in $\mathrm{GaAs}_{\text {and }} \mathrm{Al}_{x} \mathrm{Ga}_{1-x}$ As alloys // Ibid. - 1988 . - 61. - P. 873-876.

168. Dekura H., Shirai K., Yanase A. Metallization of $\alpha$-boron by hydrogen doping // J. Phys.: Conf. Ser. - 2009. - 176. - P. 012005 (10 p.).

169. Werheit H., de Groot K., Malkemper W., Lundstroem T. On n-type $\alpha$-rhombohedral boron // J. Less-Common Metals. — 1981. - 82. - P. 163-168.

170. Matsuda H., Nakayama T., Kimura K. et al. Structural and electronic properties of Li- and $\mathrm{Cu}$-doped $\beta$-rhombohedral boron constructed from icosahedral and truncated icosahedral clusters // Phys. Rev. B. - 1995. - 52. - P. 6102-6110.

171. Nakayama T., Matsuda H., Kimura K., Ino H. Mössbauer spectroscopy and electrical conductivity of Fe-doped $\beta$-rhombohedral boron // J. Solid State Chem. — 1997. — 133. P. 342-346.

Nanoscience and Nanotechnology Center,

Received 28.01.10

ISIR, Osaka University 